Review Article

\title{
A Review on Current Status of Stability and Knowledge on Liquid Electrolyte-Based Dye-Sensitized Solar Cells
}

\author{
Frédéric Sauvage ${ }^{1,2}$ \\ ${ }^{1}$ Laboratoire de Réactivité et Chimie des Solides, Université de Picardie Jules Verne, CNRS UMR 7314, 33 rue Saint Leu, \\ 80039 Amiens, France \\ ${ }^{2}$ Institut de Chimie de Picardie (ICP), CNRS FR 3085, 33 rue Saint Leu, 80039 Amiens, France
}

Correspondence should be addressed to Frédéric Sauvage; frederic.sauvage@u-picardie.fr

Received 13 August 2014; Revised 25 September 2014; Accepted 29 September 2014; Published 27 November 2014

Academic Editor: Mohamed Sarakha

Copyright (C) 2014 Frédéric Sauvage. This is an open access article distributed under the Creative Commons Attribution License, which permits unrestricted use, distribution, and reproduction in any medium, provided the original work is properly cited.

\begin{abstract}
The purpose of this review is to gather the current background in materials development and provide the reader with an accurate image of today's knowledge regarding the stability of dye-sensitized solar cells. This contribution highlights the literature from the 1970 s to the present day on nanostructured $\mathrm{TiO}_{2}$, dye, Pt counter electrode, and liquid electrolyte for which this review is focused on.
\end{abstract}

\section{Introduction}

The photovoltaic effect was discovered by the French scientist Antoine Cesar Becquerel in 1839. His observations were presented two subsequent times at the Academie des Sciences in Paris by his son Alexandre Edmond [1]. In their experiences, they shared the observations of an intriguing phenomenon related to the generation of current flowing when setting two platinum plates in contact with an aqueous acidic galvanic cell under illumination. This generation of a galvanic current under light occurs when the surface of one of the two electrodes is modified by halide vapor (iodide, chloride, and bromide). Depending on the experimental procedure for this deposition, they noticed a current flowing in one or in the other way when placed under illumination, likely owing to a halide film exhibiting $\mathrm{n}$ or $\mathrm{p}$ characteristics. For a long time, this starting point of the photovoltaic effect was considered as a scientific curiosity. A mechanistic explanation to account for this effect was drawn by A. Einstein in 1905, who obtained his first Nobel Prize in Physics for his theory describing the origin of the photoelectric effect in 1921. At that time nobody envisioned that the photonic field would become a new area of strong fundamental and applied researches from which the underlying technologies would be a stake for human beings. The starting point for PV applications goes back to the Cold War and the two superpowers' irrational objective to become the first nation to invade the Moon. Thanks to a worldwide support for billions of dollars, Chapin Pearson and Fuller from Bell Laboratories pioneered the silicon p$\mathrm{n}$ technology, paving the way to a substantial enhancement in the light-to-electricity power conversion efficiency (PCE) compared to the selenium-based electrodes exhibiting at best ca. $1 \%$. The principal objective of this new $\mathrm{p}-\mathrm{n}$ Si technology was to supply the spatial vehicles in energy by making use of extraterrestrial sun power. With its $1.1 \mathrm{eV}$ indirect bandgap affording panchromatic light absorption, they first demonstrated $4.5 \%$ power conversion efficiency in 1954 and $6 \%$ a few months later and even $8 \%$ was reported in the pioneering patent published in 1957 [2, 3]. Solely one year was required for technological transfer to Western Electric. They were the first to commercialize the product to a "large" public with small systems of $14 \mathrm{~mW}$ exhibiting $2 \%$ conversion efficiency for $25 \$(1500$ \$ per W).

Photovoltaic research intended public democratization after the two petrol crises and the ensuing financial crises in 1973 and 1979. Because of the soaring price for crude petrol and the public awareness of its limitations in terms of price stability and availability on Earth, research on alternative lowcost energy production and storage has been prompted. This has largely contributed to the development of PV but also 


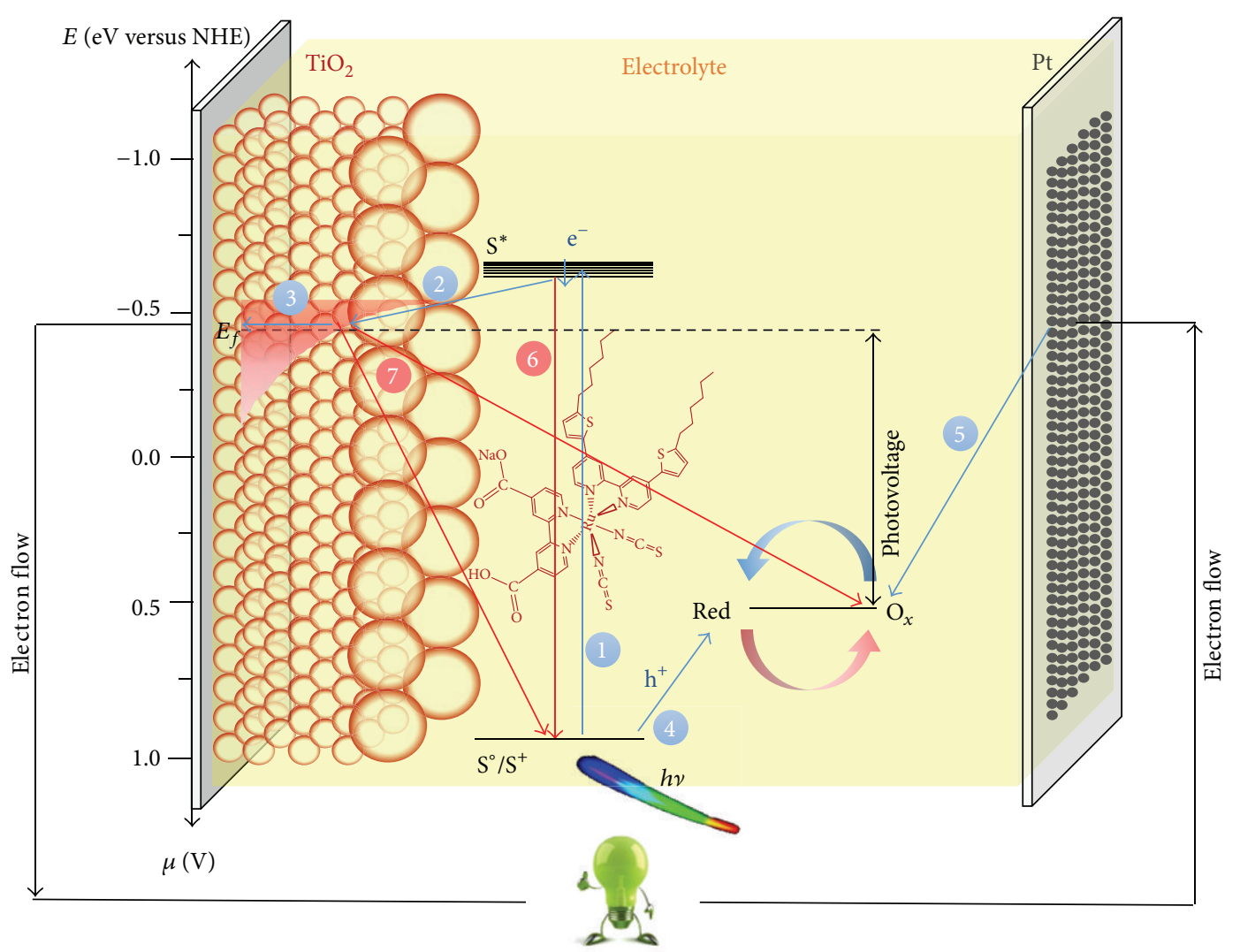

FIGURE 1: Schematic of dye-sensitized solar cell principle including the favorable charge transfer pathways in blue and the loss pathways in red.

of electrochemical batteries through the discovery of electrochemical insertion compounds which are currently used in lithium and lithium-ion technology. The most prospective low-cost PV technology is the third generation developed at the end of the 1980s. Organic PV (OPV) and hybrid organic/inorganic dye-sensitized solar cells are fulfilling not only these low-cost expectations and low environmental footprint requirements but also the easy processing, promising a fast technological transfer. What the history tends to forget is that forward-thinking Elliot Bermann envisioned already organic PV back in the late 1960s. He was supported by Exxon Company which integrated prospection for PV cutting-edge research relevant for 30 years ahead in their development projects. They rapidly cost-cut the conversion price by 5 times for the first two years' activity (from 100 to $20 \$ / \mathrm{W}_{\mathrm{p}}$ ).

This review is dedicated to the second member of the third generation, namely, dye-sensitized solar cells (DSCs) [4]. Its working principle lies in complete disruption with the other technologies: polycrystalline materials of large bandgap are used, high purity of the materials is not necessarily required, nanocrystalline semiconductors contain large amount of point defects, the working principle relies on electrochemical processes, exciton separation and transport are detached processes, and finally no internal electric fields onset the charge separation (Figure 1). The original idea of providing light sensitiveness to larger bandgap semiconductors has more than one hundred years' history. It has been prompted by Professor Vogel who pioneered a dye-sensitized silver halide emulsion for practical use in argentic photographic films [5]. This principle was turned away from its primary scope to energy related applications in particular by Gerischer and Tributsch in 1968 and 1972 who used ZnO single crystals sensitized by chlorophyll [6-8]. New impetus was finally given by O'Regan and Graetzel who published on the sensitization of mesoscopic film of nanocrystalline anatase $\mathrm{TiO}_{2}$ particles enabling, in association with red heteroleptic ruthenium (+II) polypyridyl complexes, a remarkable enhancement in the light harvesting properties of the photoanode [4].

High photoelectrochemical stability of DSC was rapidly supported by the fact that $\mathrm{Ru}(+\mathrm{II})$ polypyridyl complexes in association with $\mathrm{TiO}_{2}$ or $\mathrm{ZnO}$ can endure over $10^{7}$. $10^{8}$ turnovers of electron injection from dye excited state to electron acceptor levels in the semiconductor which in turn would guarantee more than 10 years' lifetime of the panel [9]. Rapidly passing the threshold of $10 \%$ power conversion efficiency (PCE) in 1993 [10], despite endless efforts on material development, the efficiency had stagnated for a long time in the range of $11.0-11.5 \%$ [11-16] before scoring three new subsequent records, first $12.3 \%$ and $13.0 \%$ under A.M. $1.5 \mathrm{G}$ conditions $\left(100 \mathrm{~mW} / \mathrm{cm}^{2}\right)$ using organic dye molecules in association with a stronger oxidant redox active cobalt polypyridyl complex $[17,18]$. More recently, certified $14.1 \%$ and even certified $17.9 \%$ PCE have been achieved by 


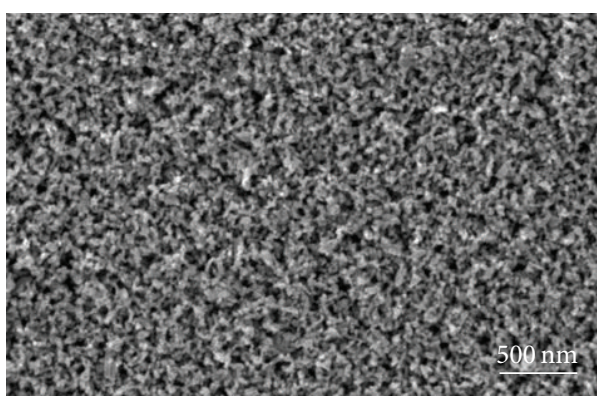

(a)

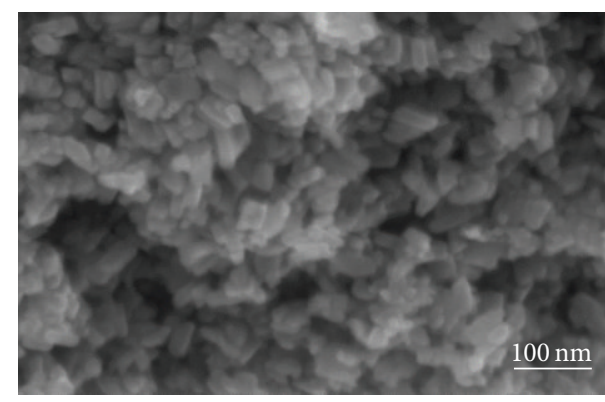

(b)

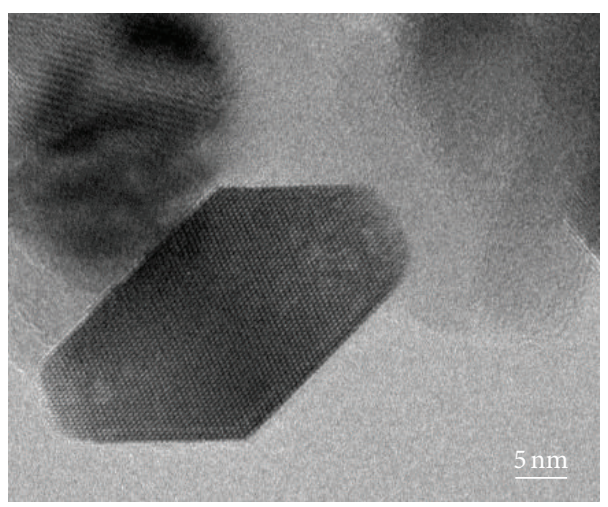

(c)

FIGURE 2: Scanning electron micrographs from (a) top view and (b) cross section of a typical mesoporous $\mathrm{TiO}_{2}$ film used as a photoanode in dye-sensitized solar cells. (c) High resolution transmission electron micrograph of $\mathrm{TiO}_{2}$ nanocrystal prepared by hydrothermal synthesis used in dye-sensitized solar cells.

replacing the dye with a hybrid organic/inorganic lead halide perovskite absorber and the liquid electrolyte by a solid hole transporting material (HTM) $[19,20]$ giving birth to a new technology called perovskite solar cells, for which progresses are remarkably fast.

Beside these excellent performances of light-to-electricity power conversion efficiency which clearly meets the standard requirement for market introduction, the race for highest PCE outshined the requirement for high stability and ageing predictability for mass industrialization in many aspects. The much lower number of publications in this area witnesses this deficiency. Matsumura et al. in 1980 already suspected issues of dye stability in devices artificially mimicking the photosynthetic process as dye-sensitized solar cells [21].

The scope of this review is to provide the reader with an overview about the current material progress which has been realized and the knowledge acquired on the stability issues of dye-sensitized solar cell technology. In this review, we will outline the recent development made in dyes and in electrolyte formulation. We will also gather the actual knowledge regarding the degradation mechanisms which are the source of efficiency decreases under accelerated ageing protocol (IEC61646). The review is then separated into three independent sections: a rapid reminder about the principle of dye-sensitized solar cells including research progress in the different cell components, an overview about the development of new electrolytes based on solvent and solvent-free formulation, and a description of the current understanding on the degradation mechanisms in dye-sensitized solar cells.

\section{Dye-Sensitized Solar Cells Principle: Role and Progress in the Different Components}

A schematic presentation of the operating principles of the DSC is given in Figure 1. At the heart of the electrochemical system, a mesoscopic layer of anatase $\mathrm{TiO}_{2}$ is sintered together to provide efficient electronic transport. The layer is typically composed of well-dispersed $20-30 \mathrm{~nm}$ size particles of anatase $\mathrm{TiO}_{2}$ sheltered by a scattering layer constituted of $c a .400 \mathrm{~nm}$ particles whose role is to scatter unabsorbed photons (Figure 2). Attached to the surface of the nanocrystalline film is a monolayer of the light sensitive dye. Photoexcitation of the latter induces charge separation, ultrafast femto/picosecond electron injection into the conduction band of the oxide, and hole capture by the reductive redox species composing the electrolyte. This regeneration reaction enables recovering the original oxidation state of the dye. For a sufficient concentration of reductive species, this reaction is fast enough to prevent the recapture of the conduction band electron by the oxidized dye and to hamper dye degradation. The role of the dye is then pivotal for the cell operation as it will govern light absorption ability of the device. The main family of redox couples used in DSC is 
the two-electron system $\mathrm{I}_{3}{ }^{-} / \mathrm{I}^{-}$. Subsequently for dye regeneration, tri-iodide diffuses towards the counter electrode and collects two electrons from the external circuit to form back iodide. The counter electrode is typically supported by electrocatalytic platinum nanoparticles reducing the charge transfer resistance for I-I bond breaking.

Alternatives to anatase $\mathrm{TiO}_{2}$ nanoparticles have been investigated. The most evident approach was to explore the two other main polymorphs of $\mathrm{TiO}_{2}$ : brookite [22] and rutile, where the latter can enhance the scattering characteristics of the reflecting layer owing to its higher refractive index [23]. Alternatively, $\mathrm{ZnO}$ [24-43], $\mathrm{SnO}_{2}$ [44-48], $\mathrm{Nb}_{2} \mathrm{O}_{5}$ [4955], and $\mathrm{In}_{2} \mathrm{O}_{3}$ [56] were also proposed along three other ternary metal oxides $\mathrm{SrTiO}_{3}$ [57-59] and $\mathrm{BaSnO}_{3}$ perovskites [60] or the spinel $\mathrm{ZnSn}_{2} \mathrm{O}_{4}[61,62]$. So far, the anatase $\mathrm{TiO}_{2}$ remains the leading contender photoanode as it affords the best performances of charge collection. The optimization of this charge collection efficiency has been the stake in research activities in the mesostructuration of the photoanode or by introducing additional point defects through aliovalent doping. The reduction of particles dimensionality offers faster electron transport when the photoanode is composed of vertically aligned nanowires or nanotubes [63-71]. The synthesis of $\mathrm{TiO}_{2}$ beads leads to the most spectacular improvements resulting from the excellent particles interconnections, shortened mass transport pathways into the mesopores, and combination of light scattering ability and high surface area offering improved light confining properties of the photoanode $[16,72-74]$. Remarkable efficiencies exceeding 11\% (A.M. $1.5 \mathrm{G}$ ) were obtained on optimized beads in combination with high molar extinction coefficient C101 or C106 ruthenium dyes.

The strategy to introduce point defects relies on the high electronic sensitiveness to doping of the $3 \mathrm{~d}^{0}$ electronic configuration adopted by the $\mathrm{Ti}^{4+}$. The literature in this topic for DSC extends rapidly, even though this approach was proscribed for a long time as it could lead to a harmful increase in the density of free carriers. However, close to thermodynamic synthetic methods are employed which maintain $\mathrm{TiO}_{2}$ a $n$-type semiconductor regardless of the dopant. It also allows charge compensation mechanism to maintain a low concentration carriers [75]. We can list a series of hypervalent cations which have been successfully incorporated into the anatase crystal structure: $\mathrm{W}^{6+}[76], \mathrm{Nb}^{5+}$ [77-80], and $\mathrm{Ta}^{5+}$ [81], subvalent cations: $\mathrm{Zn}^{2+}$ [82], $\mathrm{Cr}^{3+}$ [83], $\mathrm{Fe}^{3+}$ [84], $\mathrm{Sc}^{3+}$ [85], $\mathrm{Y}^{3+}[86]$, and $\mathrm{Ga}^{3+}$ [87], or isovalent cations such as $\mathrm{Sn}^{4+}[88]$ and $\mathrm{Ce}^{4+}[89]$. The common observation is that hypervalent doping affects the energy of acceptor trap states. A careful control of dopant concentration can therefore adjust the trap energetics and thus is favorable in some cases to accelerate the charge injection. By contrast, subvalent dopants influence neither the energy nor the distribution of traps (Figure 3). With the appropriate type of dopant and concentration, improvement of charge collection efficiency can be achieved, thus contributing to improve the power conversion efficiency, even though the efficiencies reported so far are still lying below $10 \%$.
Efforts to replace iodine/iodide redox couple have been motivated to reduce the nearby $600 \mathrm{mV}$ energy loss from improper energy alignment between the dye HOMO level and the thermodynamic redox potential of iodine/iodide. It is secondarily motivated by the strong corrosive character of iodine and its deep orange coloration penalizing the blue light conversion of the solar spectrum. A significant reduction of this loss-in potential can bring the DSC to pass the threshold of $20 \%$ power conversion efficiency [90]. Figure 4 gathers the actual redox molecules and hole transporting materials proposed so far, listed in energy scale. The closely related two electrons $\mathrm{Br}_{3}{ }^{-} / \mathrm{Br}^{-}$have been suggested despite their high corrosive character [91-93]. In combination with carbazolebased sensitizers, Li et al. achieved DSC cells going beyond the $1 \mathrm{~V}$ photovoltage threshold. The sulfide/polysulfide redox couple is typically used for quantum-dot solar cells [94] and the alternate disulfide/thiolate redox couple showed appealing features in combination with ruthenium and organic dyes [95-97]. Another one-electron redox system was investigated, namely, the cobalt $(+\mathrm{III} /+\mathrm{II})$ polypyridyl complexes [98-103], copper [104], iron [105], or nickel [106]. Fast redox couple based on nitroxide was proposed by Zhang et al. [107].

The output voltage is limited in principle by the dye absorption bandgap value $(1.5 \mathrm{eV}<\mathrm{Eg}<2.5 \mathrm{eV})$. The integration of cobalt complexes has been beneficial to boost the photovoltage of champion devices. It is interesting to comment that the braking efficiency record in DSC by means of photovoltage improvement does not differ from the other single junction technology for which new records were systematically reached from a photovoltage improvement.

The central role of the sensitizing dye molecule generates demands in terms of the triptych chemical, electrochemical, and photoelectrochemical properties. The dye should of course combine chemical and photoelectrochemical stability but should also possess a high molar extinction coefficient with panchromatic light absorption and adequate HOMO/LUMO energy alignments. The pioneering work at EPFL presented a series of ruthenium polypyridyl complexes among the ubiquitous N719 and Z907 dyes which are benchmark sensitizers still today [108]. Molecular ligand engineering for ruthenium dyes was judiciously scrutinized by different groups to tune the spectral response of the sensitizers either by introducing a ligand with a low-lying $\pi^{*}$ molecular orbital and by destabilization of the metal $t_{2 g}$ orbitals through the introduction of a strong donor unit (Figure 5). N719 and related sensitizers are typically anchored onto $\mathrm{TiO}_{2}$ according to a bidentate mode [109]. It signifies that two of the four carboxylic acid functions remain unbounded, thus not participating efficiently in the photon-induced charge releasing into $\mathrm{TiO}_{2}$. To address this issue, one approach lies in the replacement of one of the two dicarboxybipyridyl units by an ancillary ligand displaying a slight donating character at the excited state while including a long alkyl chain to improve the dye solubility, to provide a hydrophobic character for longer term stability [110, 111], and to reduce iodine access to the surface for hampering recombination processes. It was also found that enhancement of 

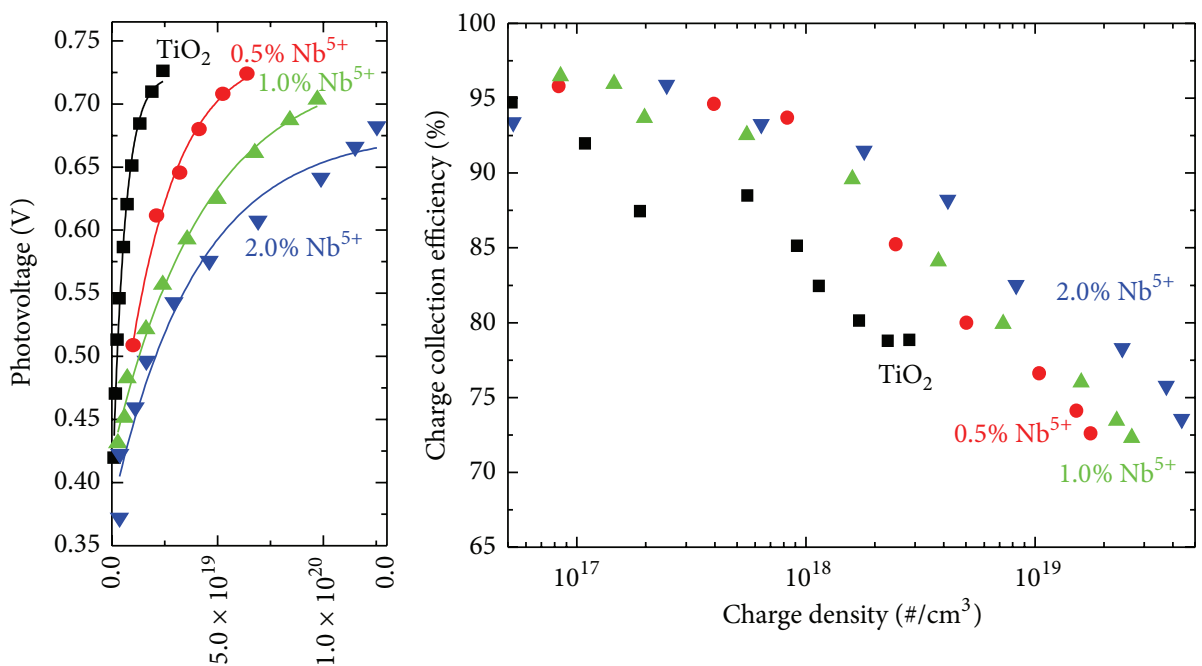

$\operatorname{DOS}\left(\# / \mathrm{cm}^{3}\right)$
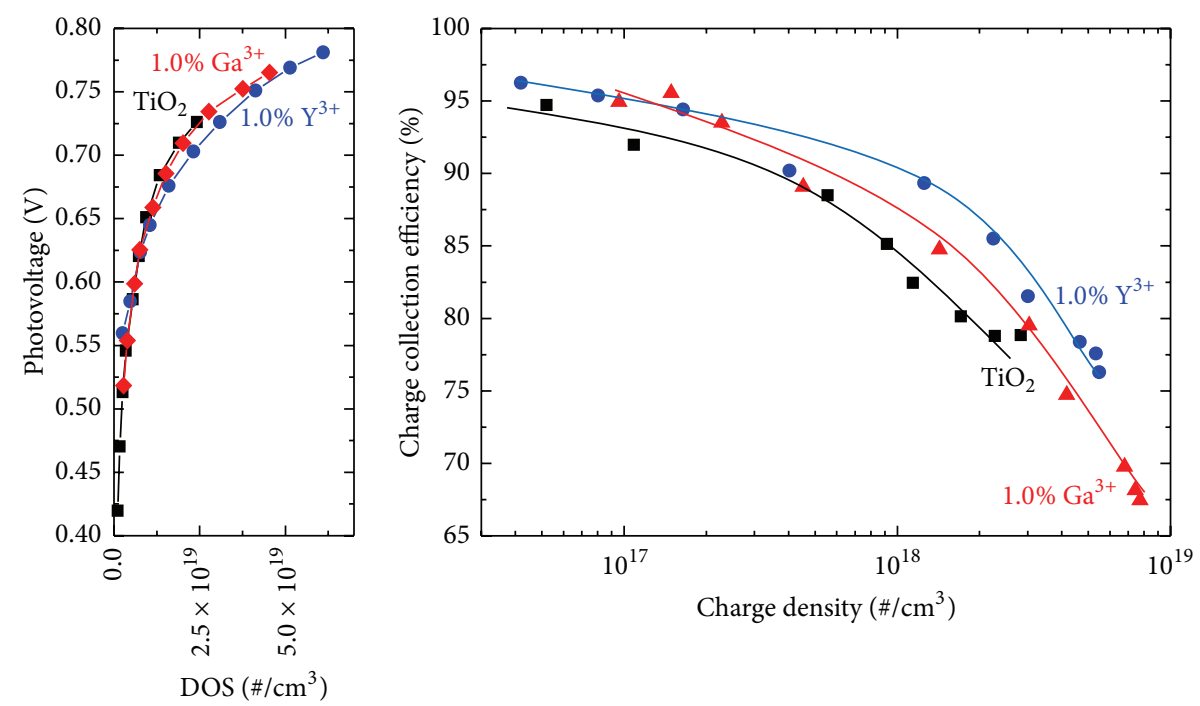

FIgURE 3: Effect of doping $\mathrm{TiO}_{2}$ by $\mathrm{Nb}^{5+}, \mathrm{Ga}^{3+}$, and $\mathrm{Y}^{3+}$ on energy and distribution of trap states and on charge collection efficiency.

the $\pi$-conjugation in the ancillary ligand not only exerts an energetic stabilization of the LUMO levels, thus redshifting the dye absorption, but also favorably affects the molar extinction coefficient of the dye reaching more than $20000 \mathrm{M}^{-1} \cdot \mathrm{cm}^{-1}[12,15,112-115]$. The integration of this second generation of dyes paved the way to improved performances in terms of light harvesting and power conversion efficiency. Well above $11 \%$ power conversion efficiency was achieved and excellent stability data reported at $60^{\circ} \mathrm{C} / 100 \mathrm{~mW} \cdot \mathrm{cm}^{-2}$ conditions. The extension of conjugation in the acceptor ligand by going from bipyridine, terpyridine (e.g., N749) to quaterpyridine (e.g., N1044) contributes to a broadening in the absorption of the dye affording visible light panchromatic response [116-118], unfortunately at the expense of the molar extinction coefficient.

The second option to tune the complex absorption towards the red consists in destabilizing the $t_{2 g}$ orbitals of the ruthenium by the introduction of a stronger donor unit than thiocyanate. Many attempts to replace the thiocyanate donor ligands have been made and motivated also by the fact that the monodentate NCS is believed to be the weakest part of the complex from a chemical point of view. For long time, these efforts had yielded limited success as the conversion efficiency remained well below few percent [119]. A paradigm arose from the YE series developed by Bessho et al. who achieved $10.1 \%$ power conversion efficiency under standard illumination conditions (A.M. 1.5 G) [120]. The lowest energy MLCT band is red-shifted by $25 \mathrm{~nm}$ and contains a new absorption band at $485 \mathrm{~nm}$ with a remarkable molar extinction coefficient. This new band is characterized by an electronic transition from HOMO, which has a sizable $\pi$-orbital contribution from the cyclometalated ligand, and the LUMO formed by a set of $\pi^{*}$ orbitals localized on the bipyridines ligands evidencing strong electronic coupling with acceptor states in $\mathrm{TiO}_{2}$. These features explain the high photocurrent in the range of $17 \mathrm{~mA} / \mathrm{cm}^{2}$ and the photovoltage 


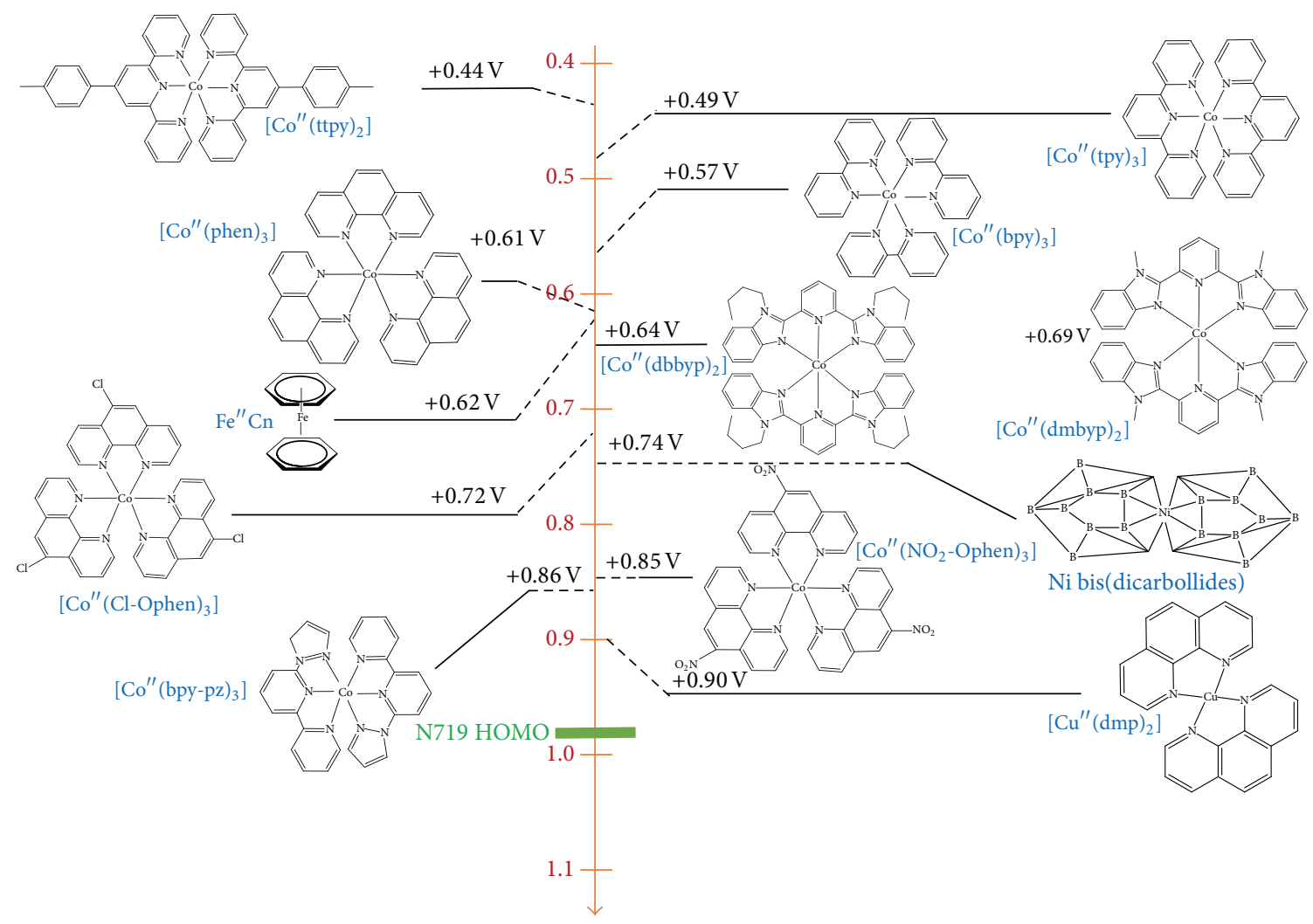

Potential (V versus NHE)

(a)

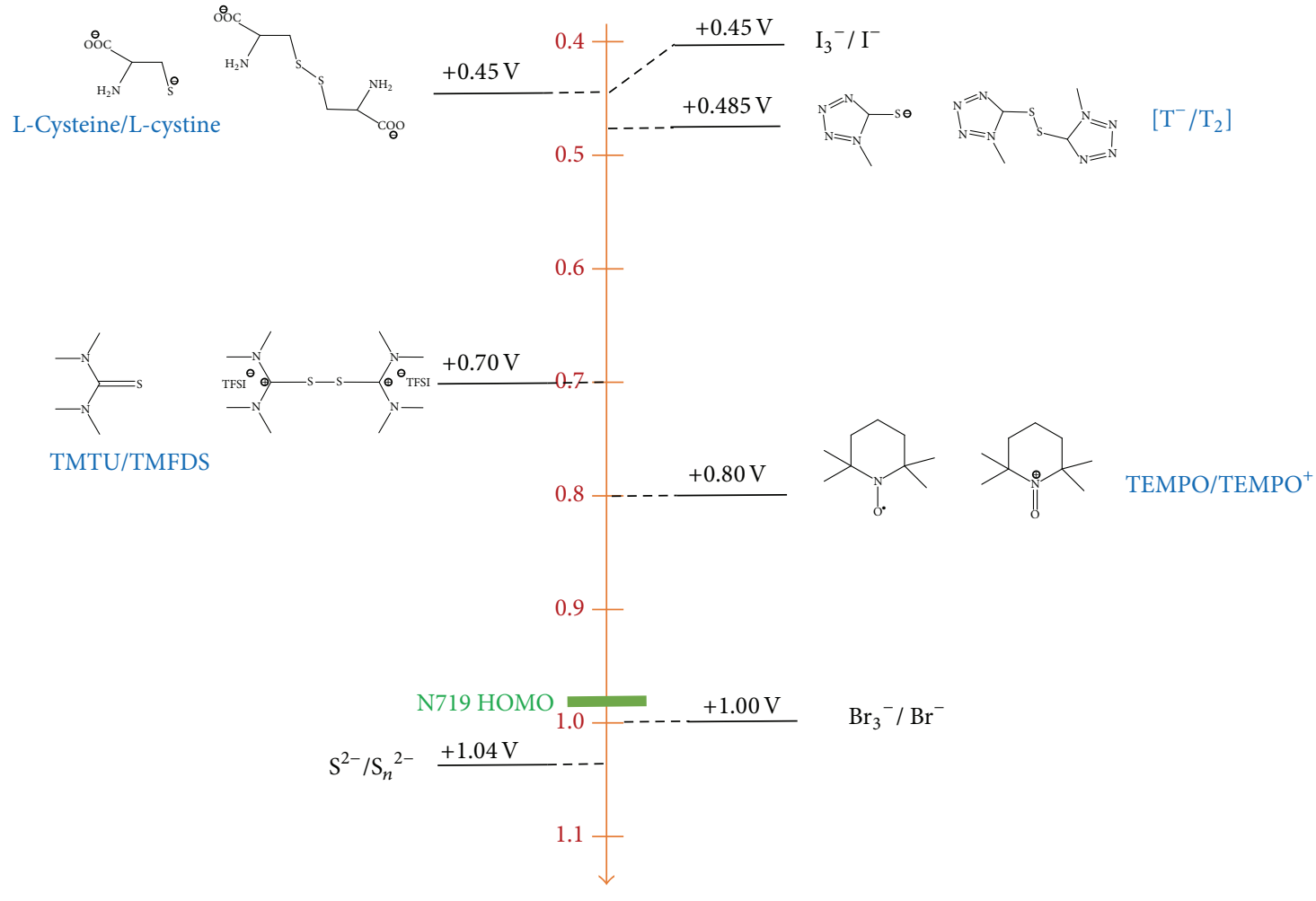

Potential (V versus NHE)

(b)

FIGURE 4: Scale of chemical potential for the main (a) redox complexes and (b) redox molecules used in dye-sensitized solar cells. 


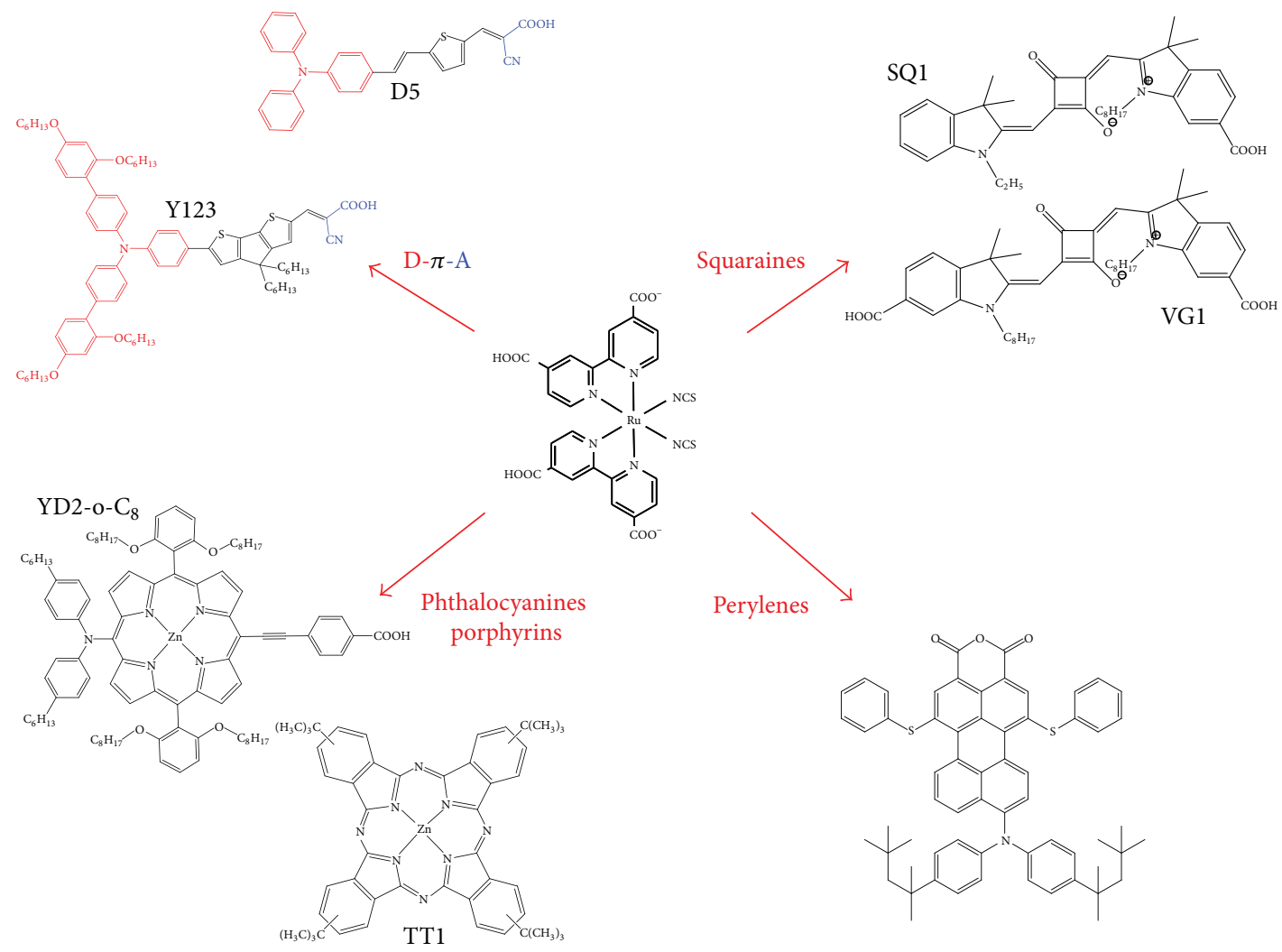

FIGURE 5: Main families of different organic dyes developed for dye-sensitized solar cells.

exceeding the threshold of $800 \mathrm{mV}$. After this work, another family of NCS-free ruthenium structures was developed by Bomben et al., who reached close to $10 \%$ efficiency [121]. The removal of NCS ligands altogether in tridentate cyclometalated ligands also provides an enhancement in the absorption ability of the complex. This was demonstrated in the series of TF-dyes compared to the thiocyanate-related N749 (so-called black dye) [122]. With TF-dyes, Chou et al. reached $10.7 \%$ power conversion efficiency with photocurrent densities attaining as high as $22 \mathrm{~mA} / \mathrm{cm}^{2}$. We can regret the actual lack of knowledge about the stability of all these new complexes, either because they are not offering good stability in cells or simply because they were not investigated.

In order to bypass the price for ruthenium metal which continuously beats records and to address the synthetic difficulties intrinsic to organometallic compounds often requiring lengthy and costly purification processes incompatible for real mass production, metal-free organic chromophores have been proposed. Some of them are actually meeting the ruthenium sensitizers in terms of power conversion efficiency and even stability. They exhibit significantly higher molar extinction coefficient than ruthenium dyes, lying in the range of 20000 to $400000 \mathrm{M}^{-1} \cdot \mathrm{cm}^{-1}$. Four main families have been reported: porphyrins and the closely related phthalocyanines (coordinated with zinc or not), donor- $\pi$-acceptor (D- $\pi$-A) assembly, squaraines, and perylenes (Figure 5). Note that other families of organic chromophores have also been reported: coumarins which approached $\eta=7.7 \%$ [123], indolines, and natural pigments among which are anthocyanin, flavonoid, carotenoid, and chlorophyll [124].

$\mathrm{D}-\pi$-A structures actually stand out from the others as they combine high power conversion efficiencies beyond $10 \%$ $[125,126]$ and stability standard passing even the accelerated ageing test of $85^{\circ} \mathrm{C} /$ dark (Y123 dye). One key unit in the design of $\mathrm{D}-\pi-\mathrm{A}$ originated from the introduction of cyanoacrylic function as an acceptor group which enabled extending light absorption ability of the dye compared to the related coumarin $\mathrm{D}-\pi-\mathrm{A}$ [127]. It provides around $25 \%$ more short-circuit current density and exhibits a molar extinction coefficient close to $100000 \mathrm{M}^{-1} \cdot \mathrm{cm}^{-1}$ at $552 \mathrm{~nm}$. Sensitizers having an intense absorption band in the near-infrared region can be typically acquired through phthalocyanines which are reaching absorption maxima to $700 \mathrm{~nm}$. Squaraines dyes can even get close to $800 \mathrm{~nm}[128,129]$. Despite these interesting absorption profiles, NIR dyes have typically showed unimpressive power conversion efficiencies due to either too strong aggregation and lack of directionality in the excited state for the phthalocyanines [130] or issues for fast electron injection in the case of the NIR squaraines. This is explained by a too strong energetic stabilization of the $\pi^{*}$ orbital delocalized throughout the dye structure. For these reasons, this call for the development of new semiconductor having lower lying energy conduction band edge for endorsing fast electron transfer. A very recent in-depth review dedicated to metalfree sensitizers can be found in [131]. 


\section{Liquid Electrolyte Development Based on Solvent and Solvent-Free Formulation for Stable Devices}

Champion efficiencies reported above are systematically obtained in conjunction with an electrolyte based on a volatile solvent. Pure acetonitrile or acetonitrile/valeronitrile solvent mixtures are often preferred. Their intrinsic characteristics, mostly in terms of volatility, cannot guarantee enough stability to pass the accelerated IEC61646 protocol. The excessive vapor pressure exerted shortcomings to the cell sealing even at temperatures well below $60^{\circ} \mathrm{C}$, besides additional chemical/electrochemical reactions in cell which may occur. This volatility issue was circumvented by replacing acetonitrile with a different class of lower volatile solvents. $\gamma$-Butyrolactone (GBL), propylene carbonate (PC), propionitrile $(\mathrm{PN})$, sulfolane, butyronitrile $(\mathrm{BN})$, or 3-methoxypropionitrile (MPN) had been proposed. Their integration led to substantial device lifetime prolonging. It seems that the last two actually show the best compromise between high efficiencies and stability. The sulfolane-based electrolyte is promising for extreme conditions even though its high viscosity impedes high photocurrent production owing to mass transport limitations [132].

The electrolyte is not solely composed of iodide and iodine. It also contains two main additives. The beneficial impact of these additives on the cell performance is undeniable. However, the exact role/action in the complete cell remains speculative in some extent. Table 1 gathers the benchmark composition of nitrile-based electrolyte which is used to obtain high efficiencies or alternatively good stability for low-volatile MPN or BN solvent. Note that solvent-free ionic liquids are composed of binary or ternary eutectics melts including different components and composition than the reported in Table 1. A review was dedicated to this topic by Zakeeruddin and Grätzel [133]. The two additives typically incorporated in electrolyte are guanidium thiocyanate and a Brönsted base, namely, terbutylpyridine for high efficiency electrolyte or replaced by the N-butyl benzimidazole or the benzimidazole in some cases for stable electrolytes. The utilization of a Brönsted base affords the deprotonation of the sensitized $\mathrm{TiO}_{2}$ surface. It contributes to up-shift the quasi-Fermi level in $\mathrm{TiO}_{2}$ and therefore the open circuit voltage of the cell. N-Butyl benzimidazole in stable electrolyte composition is preferred over terbutylpyridine, regardless of whether it is in MPN or BN (Figure 6). The comparison of the two molecules suggests that they have similar strength for deprotonation since the distribution of the subconduction band energetic levels is not modified. The charge collection efficiency is similar or slightly better in the case of the terbutylpyridine for which a marginally higher electron lifetime is compensated by a lower electron transport (Figure 6). The guanidinium thiocyanate has a more subtle function. The literature often refers to the guanidinium cation going to the surface of $\mathrm{TiO}_{2}$ between the dye molecules in order to explain the improvement of charge collection efficiency. However, it is also straightforward that this additive is beneficial for the cell stability, in particular to maintain a high fill factor.
An impedance study carried out on TCO-Pt/electrolyte/PtTCO symmetric cells, performed at the laboratory, has highlighted that the charge transfer resistance evolution becomes strongly dependent on whether the electrolyte contains or not this guanidinium thiocyanate additive. Indeed, whereas the benchmark electrolyte composition containing $0.1 \mathrm{M}$ of guanidinium thiocyanate shows a slight decrease in $R_{\mathrm{ct}}$ to $c a$. $1 \Omega \cdot \mathrm{cm}^{2}$, such evolution appears in complete contrast with an electrolyte composition free of guanidinium thiocyanate (Figure 7). Beside its aforementioned function, we concluded that the guanidinium thiocyanate molecule also plays the role of a protective agent by molecular self-assembling onto $\mathrm{Pt}$ to prevent its dissolution through soluble $\mathrm{PtI}_{6}{ }^{2-}$ complexes. This is further supported by visual observation of the symmetric cell during ageing which tends to bleach at the specific area in contact with the electrolyte.

In terms of stability performances, $10 \%$ efficiency on lab cells $\left(<1 \mathrm{~cm}^{2}\right)$ with PCE retention over $95 \%$ after 1000 hours under $60^{\circ} \mathrm{C} / 100 \mathrm{~mW} / \mathrm{cm}^{2}$ light soaking experiments currently stands for the best values reported so far on lab devices. This was achieved by using either BN [134] or alternatively gelified MPN-based electrolyte [135]. Dyesol recently reported its HSS electrolyte passing even $95^{\circ} \mathrm{C} /$ dark accelerating test for 1000 hours in combination with N719 dye with efficiencies in the range of 5\% under standard illumination conditions (A.M. 1.5 G) [132].

The standard accelerated ageing tests protocol used for evaluating the stability of dye-sensitized solar cells is by default the protocol established for terrestrial thin film PV (IEC61646):

(i) 1000 hours at $85^{\circ} \mathrm{C}\left( \pm 2^{\circ} \mathrm{C}\right)$ in dark under $85 \%( \pm 5 \%)$ humidity;

(ii) 1000 hours at $60^{\circ} \mathrm{C}$ under light illumination (800$\left.1000 \mathrm{~W} / \mathrm{m}^{2}\right)$

(iii) 300 thermal cycles between $-40^{\circ} \mathrm{C}$ and $+85^{\circ} \mathrm{C}$.

Stable performances were reported over 2000 hours at $60^{\circ} \mathrm{C}$ in dark maintaining 5.5\% PCE [136], 2.5 years in outdoor conditions without specification about module efficiency [137], or 2280 hours at room temperature under $80 \mathrm{~mW} / \mathrm{cm}^{2}$ light soaking [138], or more recently Dyesol Ltd. achieved as long as 25600 hours at $55^{\circ} \mathrm{C}-60^{\circ} \mathrm{C}$ under continuous light soaking with preserving $4 \%$ efficiency [139]. Since the seminal publication by Graetzel, only very few articles have reported stability at higher temperatures, requiring, as it seems, more viscous liquids to alleviate sealing issues, as, for instance, gelified electrolyte or solvent-free ionic liquids [140-143]. Apart from the very few reports announcing this achievement, still no consensual publications are actually passing the challenging threshold of 1000 hours at $85^{\circ} \mathrm{C}$ in dark condition with efficiencies above 5\% [132, 144, 145]. Nevertheless, this assessment emphasizes on the one hand the high credibility of DSC for larger scale applications, but on the other hand, it also point out the important gap to fill in between the champion efficiencies and the stable devices for which this gap closing will require more focus on the understanding of the ageing mechanisms leading to the cell failure, and, in a next step to design specifically more 


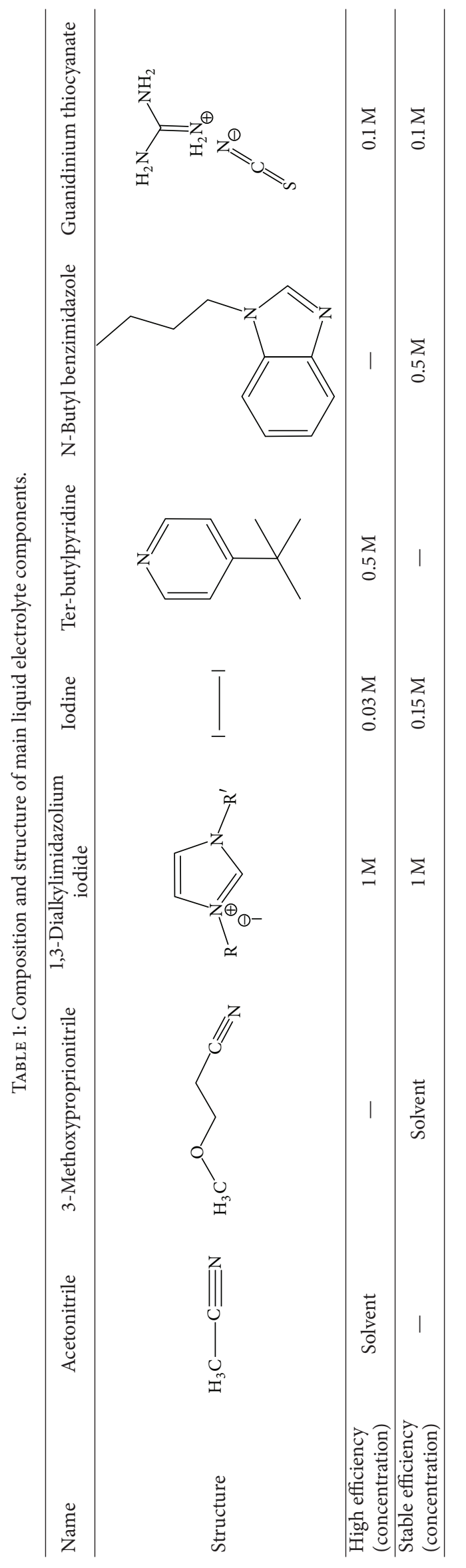



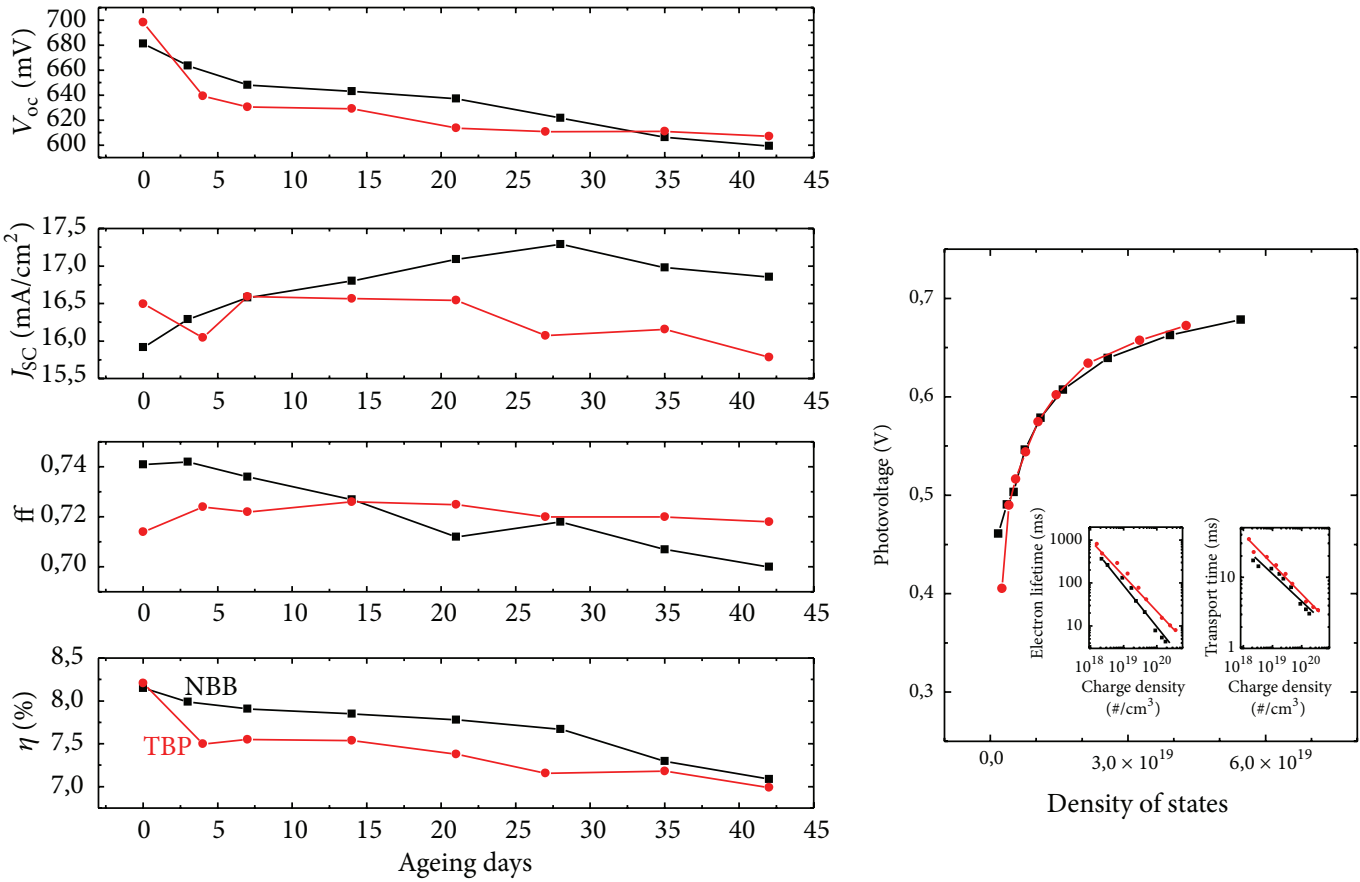

(a)
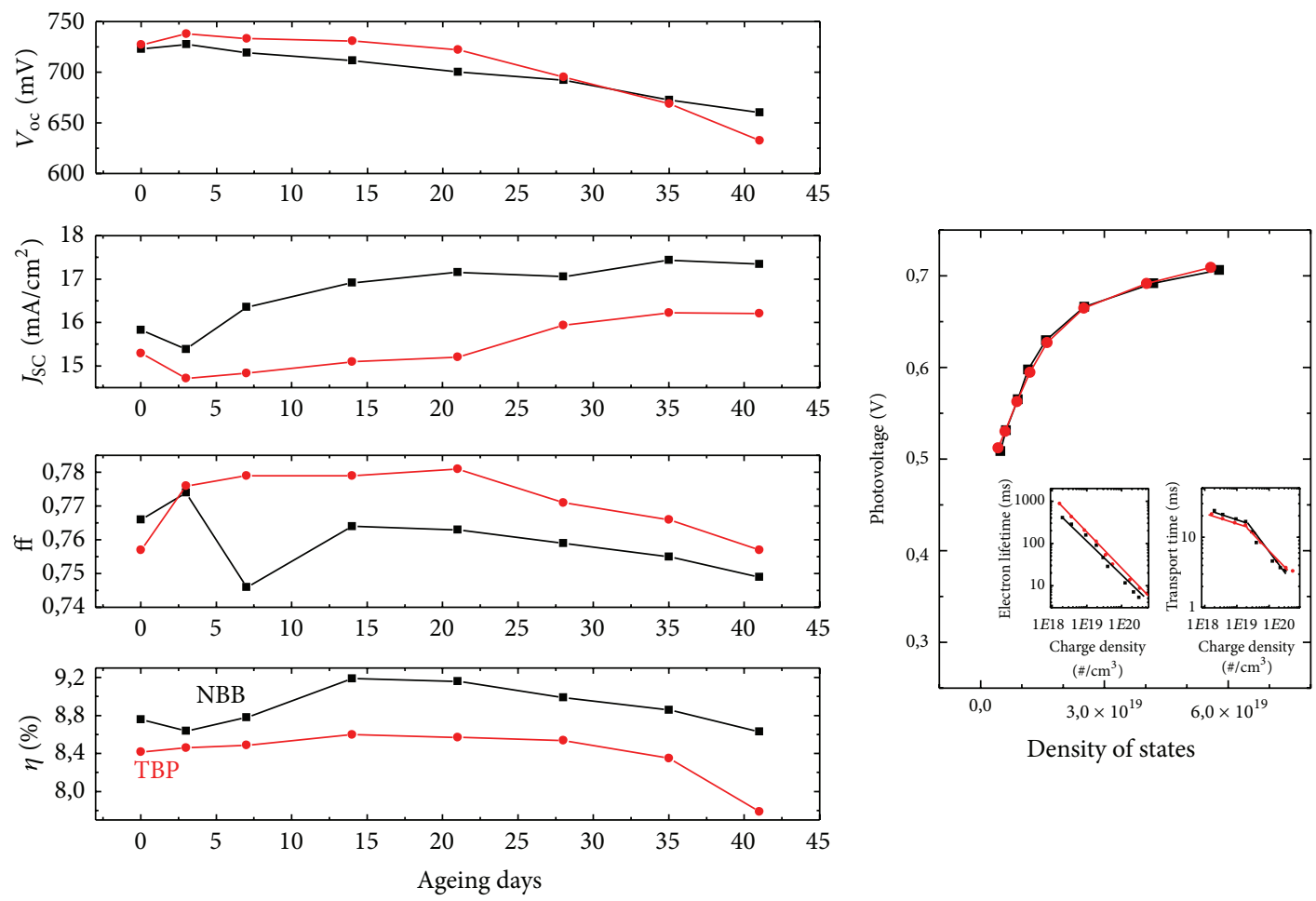

(b)

FIGURE 6: Comparison of cell characteristics during ageing at $60^{\circ} \mathrm{C} / 100 \mathrm{~mW} \cdot \mathrm{cm}^{-2}$ using an electrolyte constituted of TBP or NBB (composition: $1 \mathrm{M}$ DMII, 0.1 M GuNCS, $0.15 \mathrm{M} \mathrm{I}_{2}$, and $0.5 \mathrm{M} \mathrm{NBB} / \mathrm{TBP}$ ) in (a) 3-MPN solvent and in (b) BN solvent. A comparison of the trap state distribution and energy and a comparison of electron lifetime and transport time as a function of charge density are also included. 


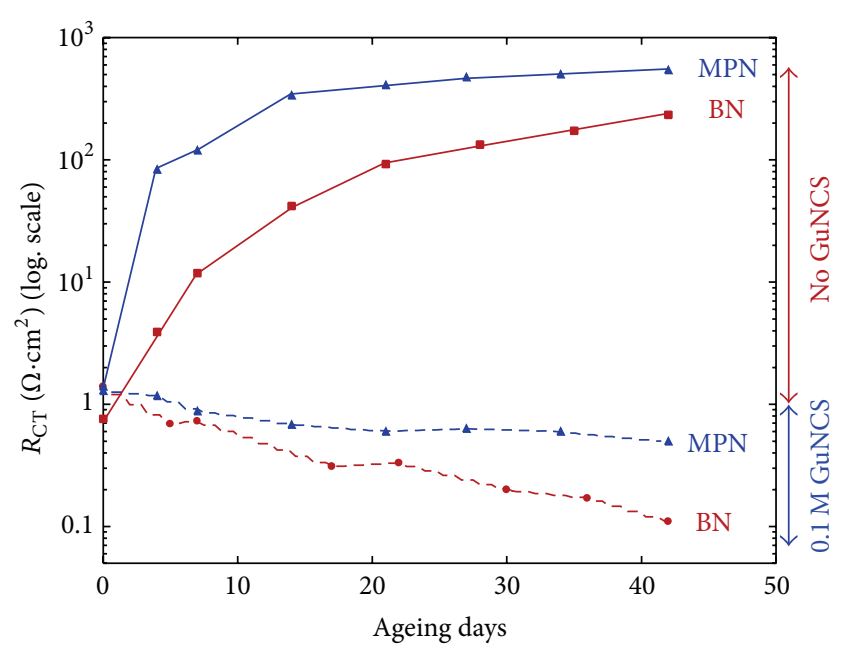

Figure 7: Evolution of the charge transfer resistance as a function of ageing time at $60^{\circ} \mathrm{C} / 100 \mathrm{~mW} \cdot \mathrm{cm}^{-2}$ measured in TCO$\mathrm{Pt} /$ electrolyte/Pt-TCO symmetric cell configuration comparing $\mathrm{BN}$ and 3-MPN-based electrolyte, with $0.1 \mathrm{M}$ GuNCS and without GuNCS.

robust and better performing molecules (i.e., ligand, solvent, additive(s) in electrolyte, etc.).

\section{Current Understanding of Chemical/Photoelectrochemical Degradation Paths}

Whereas the durability of single-crystalline and amorphous silicon modules is established to a lifetime attaining 20 years without question, the stability and ageing predictability of emerging PV technologies are still under close observation to predict at least 10 years' lifetime under working environment. Mastering the dynamics of charge transport and charge recombination that take place in dye-sensitized solar cells is a crucial issue for reaching high performances. Nevertheless the stability of each cell component taken separately and the understanding of all the chemical, electrochemical, and photochemical reactions interplay at the different material interfaces or components are a key to bring further development on DSC, not only to improve the device stability under severe ageing conditions but also to close the gap between champion and stable efficiencies. Such complete understanding of the ageing mechanisms will pave the way to the specific design of more robust components. Integrated in an advanced generation, these new materials will give impetus to DSC commercialization and broader integration into the PV panorama. Only a very few groups are actively working in this more fundamental but crucial domain. Beside the intrinsic sealing and permeability issues of the device which have been revealed to influence the device stability as will be discussed below, six distinct intrinsic features contributing to the cell degradation have been spotted in the literature (Figure 8).

(1) Likely one of the most preeminent degradation path stems from the well-known iodine consumption in electrolyte: this reaction takes place during ageing. It translates into a well-visible bleaching in coloration of the electrolyte. It is crucial to overcome this side reaction as it is one important source of failure since iodine concentration controls the kinetic for triiodide mass transport. Excessive depletion will turn to short-circuit current density limitation of the device.

(2) Dye desorption at elevated temperatures $\left(>60^{\circ} \mathrm{C}\right)$ : this possible event takes its origin from the rivalry between dye solubility in the electrolyte and the binding strength of the anchoring group upon $\mathrm{TiO}_{2}$. It can also be promoted by the ruthenium hexacoordination rupture as it will be discussed below. Water intake in the electrolyte has also been proposed to assist this dye desorption mechanism. The development of hydrophobic dyes was anticipated to go against this reaction and explained the better long term stability of Z907 versus N719.

(3) There is lack of chemical and photochemical stability of the monodentate thiocyanate ligand in heteroleptic ruthenium (+II) complexes which tends to undergo substitution reactions with different external components.

(4) There is platinum dissolution for electrolytes free of thiocyanate (cf. Figure 7).

(5) Formation of a polymeric solid electrolyte interphase (SEI) forming on $\mathrm{TiO}_{2}$ and sensitized- $-\mathrm{TiO}_{2}$ (see Figure 10 inset).

(6) UV irradiation causes direct bandgap excitation of $\mathrm{TiO}_{2}$ leading to conceivable dye or electrolyte component oxidation [137, 146]. Addition of $\mathrm{MgI}_{2}$ or $\mathrm{CaI}_{2}$ in the electrolyte was proposed to improve the electrolyte tolerance to UV irradiation [135]. It is also typical to cover the glass photoanode by an antireflecting polymer coating which also plays the role of UV filters [146].

In the following we will review in more details the two most severe issues to overcome, namely, the iodine depletion in electrolyte and the dye chemical/photoelectrochemical stability.

4.1. Iodine Consumption. Iodine consumption has been spotted by numerous groups who gave different attributions to explain this depletion. A total of eight hypotheses/observations, sometimes controversial, can be listed.

(i) Formation of $\mathrm{IO}_{3}{ }^{-}$induced by water traces [147-150]: in this case it is postulated that $\mathrm{I}_{2}$ reacts with ingress water or residual water contained in the electrolyte. It leads to the formation of the iodate anion $\left(\mathrm{IO}_{3}{ }^{-}\right)$. As commented also by some of these authors, the formation of $\mathrm{IO}_{3}{ }^{-}$has, however, never been really detected so far either by spectroscopic methods (UVVis, Raman, etc.) or by chromatography (LC/MS). Figure 9 reports an example of withdrawn aged electrolyte analyzed by LC/MS after 500 hours' ageing at 


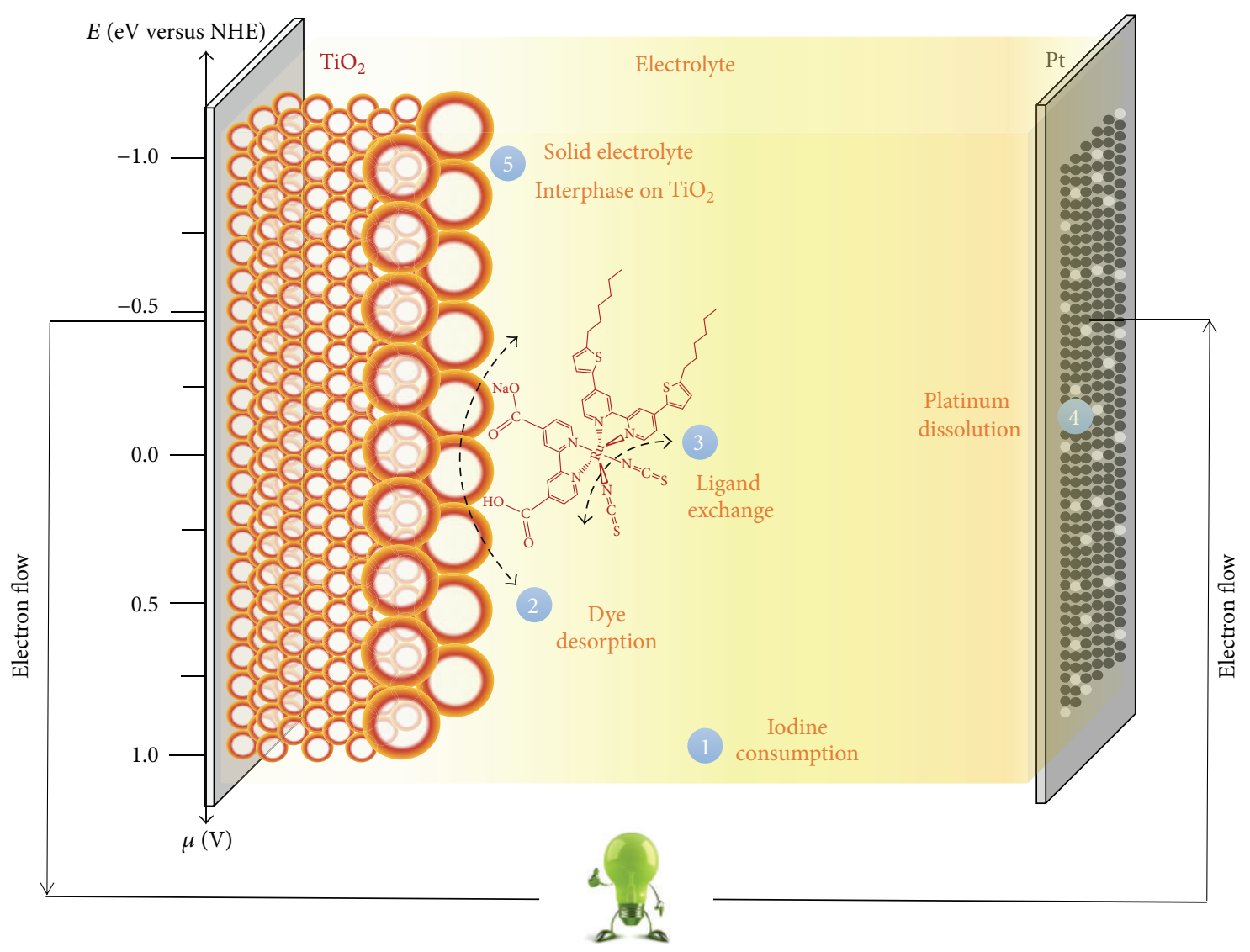

FIGURE 8: Schematic gathering the known stability issues in dye-sensitized solar cells.

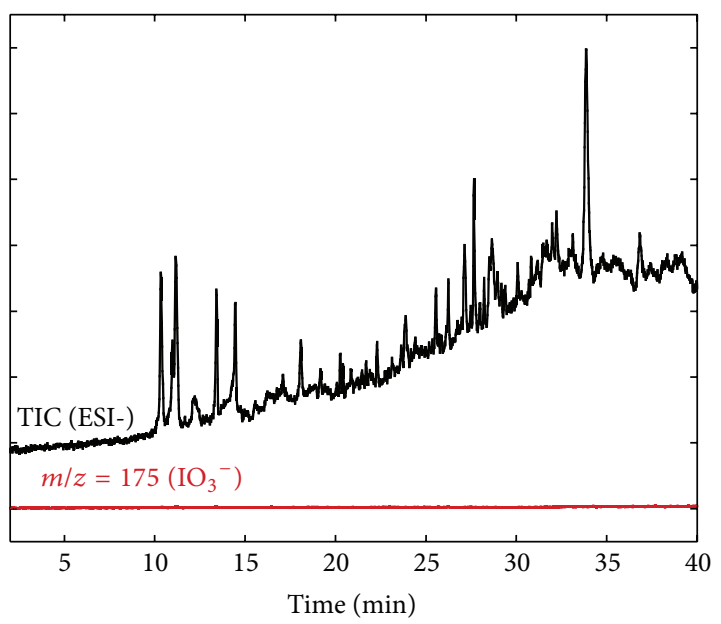

FIGURE 9: LC/MS chromatogram of aged MPN-based electrolyte in contact with $\mathrm{TiO}_{2}$ during 500 hours at $85^{\circ} \mathrm{C} /$ dark. The chromatogram for $m / z$ value of 175 is reported for comparison.

$85^{\circ} \mathrm{C}$ in dark and compared to the specific signal of $\mathrm{m} / \mathrm{z}$ value of $\mathrm{IO}_{3}{ }^{-}[151]$.

(ii) $I_{2}$ reacts with glass frit used in some technologies as a sealant [152]. The experimental evidences reported in the reference are conclusive. However, this depletion is experienced regardless of the type of sealant utilized (i.e., Bynel or Surlyn polymers, glass frit, etc.). This is therefore not the original path for this reaction even though it will contribute to this consumption.

(iii) Sublimation of molecular $\mathrm{I}_{2}$ has been proposed by different groups $[145,153,154]$. This hypothesis has been controverted by ex situ and in situ spectroscopic methods such as Raman on aged electrolyte and GC/MS or TGA/MS performed also on aged electrolyte or on electrolyte heated at $60^{\circ} \mathrm{C}$ or $85^{\circ} \mathrm{C}$ with gas output analysis. The results were suggesting the absence of any spectroscopic band or mass which could be attributed to iodine or iodide-based compounds even in form of traces [151].

(iv) Bandgap excitation of $\mathrm{TiO}_{2}$ leads to the photoelectrochemical reduction of tri-iodide [155]. This reaction would be particularly unexpected knowing that $\mathrm{TiO}_{2}$ has a strong $n$-type semiconducting character with direct bandgap excitation. This reaction takes place faster without than with dye and therefore could not be attributed to a recombination procedure between iodine and electron in conduction band. Last but not least [152], also pointed out that iodine consumption proceeds in dark and is only thermally activated as discussed below. 


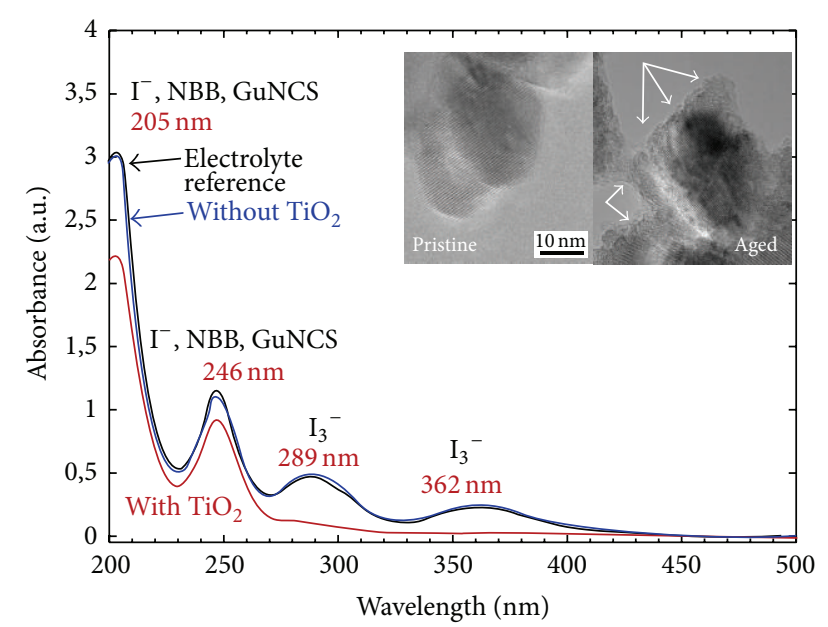

FIGURE 10: Evolution of UV-Vis absorption spectrum for reference MPN-based electrolyte (in black), electrolyte aged alone during 500 hours at $85^{\circ} \mathrm{C} /$ dark (in blue), and electrolyte aged in contact with $\mathrm{TiO}_{2}$ (in red). In inset are reported high resolution transmission electron micrographs comparing the $\mathrm{TiO}_{2}$ nanoparticles before and after ageing showing the formation of SEI layer.

(v) The electrolyte bleaching is solvent dependent. This has been clearly highlighted from the work led at Dyesol by Jiang et al. [132, 156]. The authors compared $\gamma$-butyrolactone, 3-methoxypropionitrile, and the socalled nitrile-free solvent HSS. They have concluded that iodine depletion is significantly hampered when going from $\gamma$-butyrolactone to HSS. They have also reported slower iodine consumption using tetraglyme compared to 3-MPN [156].

(vi) Iodine consumption is not an intrinsic reaction taking place in the electrolyte alone. It is triggered by the surface of $\mathrm{TiO}_{2}$ which plays a catalytic role in the electrolyte degradation [151]. The authors concluded that iodine depletion is exclusively activated by temperature while light has no action on this reaction, at least for 3-MPN-based electrolyte (Figure 10).

(vii) Iodine reacts with the electrolyte additives such as the 4-tert-butylpyridine (TBP) leading to an iodopyridinate complex and with thiocyanate ligand of the dye to form $\mathrm{I}_{2} \mathrm{NCS}^{-}$species in the particular case the electrolyte is exempt of any TBP $[157,158]$.

(viii) Formation of a solid electrolyte interphase (SEI) nucleating on the surface of $\mathrm{TiO}_{2}$ in the dye monolayer pinholes (Figure 10 inset) [151]: the authors highlighted that SEI formation traps or solvates iodine (and other electrolyte components) explaining its depletion from bulk electrolyte. It is supported by UV-Vis and XPS spectroscopies combined to ToF-SIMS which revealed on the one hand its very complex composition and on the other hand its high concentration of iodine/iodide-based species along other degraded components of the electrolyte. To the current understanding, this SEI layer is originating from the polymerization between acrylonitrile radicals leading to the formation of a very cohesive polyacrylonitrile polymer. GC/MS experiments showed that in presence of $\mathrm{TiO}_{2}$ the 3-MPN thermally disrupts to form two highly volatile compounds: acrylonitrile $\left(b p .=77^{\circ} \mathrm{C}\right)$ and methanol $\left(b p .=65^{\circ} \mathrm{C}\right)[159]$. The free radical polymerization of acrylonitrile is well-established to take place spontaneously by mild thermal activation such as temperatures in a range of $50^{\circ} \mathrm{C}$. The polymerization rate can get substantially faster in the presence of metal halide catalyst [160]. The formation of these two degradation compounds can also give a more rational explanation to the sudden electrolyte evaporation pointed out by many authors in the field, which operates at a more or less long term in the ageing, an event typically the culprit of poor cell sealing.

The literature often refers to iodine consumption in electrolyte as it is the chromatic component of the electrolyte with its characteristic strong purple color. At HOPV2014 conference our group presented that many other electrolyte components are in reality consumed. We determined by cyclic voltamperometry using a platinum microelectrode that about $50 \%$ of iodide is depleted after 500 hours' ageing at $85^{\circ} \mathrm{C}$ (Figure 11(a)), FT-IR carried out on aged electrolyte indicates that thiocyanate from guanidinium thiocyanate is almost completely depleted (Figure 11(b)), and last but not least $\mathrm{N}$-butyl benzimidazole is also quantitatively consumed (ca. 50\%) by LC/MS (Figure 11(c)) [159]. These experiments were realized looking at the interface between naked $\mathrm{TiO}_{2}$ and electrolyte. When sensitized, these reactions are still occurring but at slower rate. This was similarly experienced in the case of iodine consumption for which Asghar et al. have made careful comparison between unsensitized $\mathrm{TiO}_{2}$ and sensitized $\mathrm{TiO}_{2}$ highlighting that dye monolayer only slows down this reaction [161]. MPN-based electrolyte stability is strongly affected by the surface of $\mathrm{TiO}_{2}$ which tends to destabilize significantly the thermal stability of electrolyte components by about $50^{\circ} \mathrm{C}$ (Figure 12). The surface of $\mathrm{TiO}_{2}$ also collaterally induces gas formation as aforementioned in this review $[151,159]$.

\subsection{Chemical/Photochemical Stability of Benchmark Ruthe-} nium Sensitizers. This part is more focused on ruthenium polypyridyl complexes. Much less is known about the core stability of organic dyes. Tanaka et al. reported that major degradation in indoline-based D- $\pi$-A dye, namely, the yellow D131 chromophore, was decarboxylation of the cyanoacrylic acid anchoring group [162]. This decarboxylation reaction is contributing to dye desorption, lowering significantly the device performance whether the ageing is at $60^{\circ} \mathrm{C} / 1$ sun or $85^{\circ} \mathrm{C} /$ dark. This reaction has been attributed to harmful action of iodine or amine components to the dye. This reaction can likely be extended to some degree to the family of "push-pull" D- $\pi$-A dye, even though some of other dyes in this family have been reported to be very stable upon $60^{\circ} \mathrm{C} /$ light and $85^{\circ} \mathrm{C} /$ dark ageing conditions. Most of organic dyes are known to cause stability issues owing to their empathy to undergo fast photooxidation when they are 


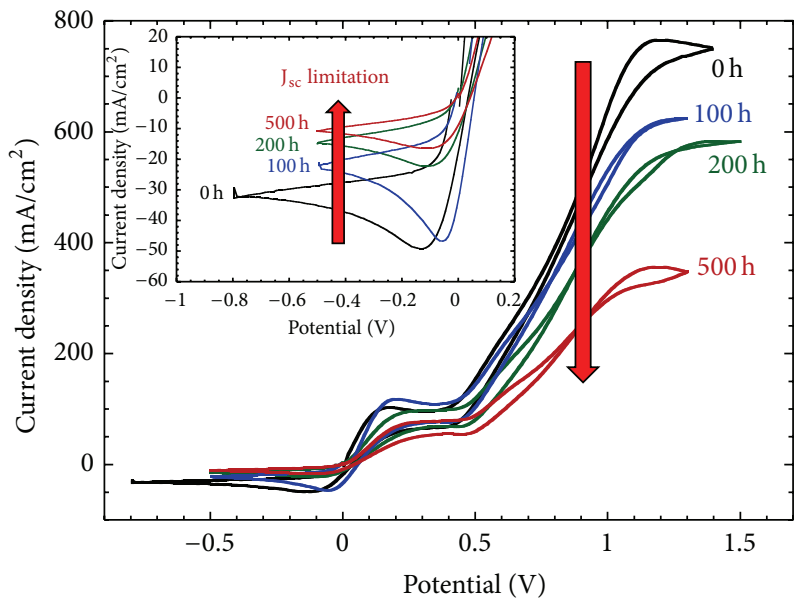

(a)

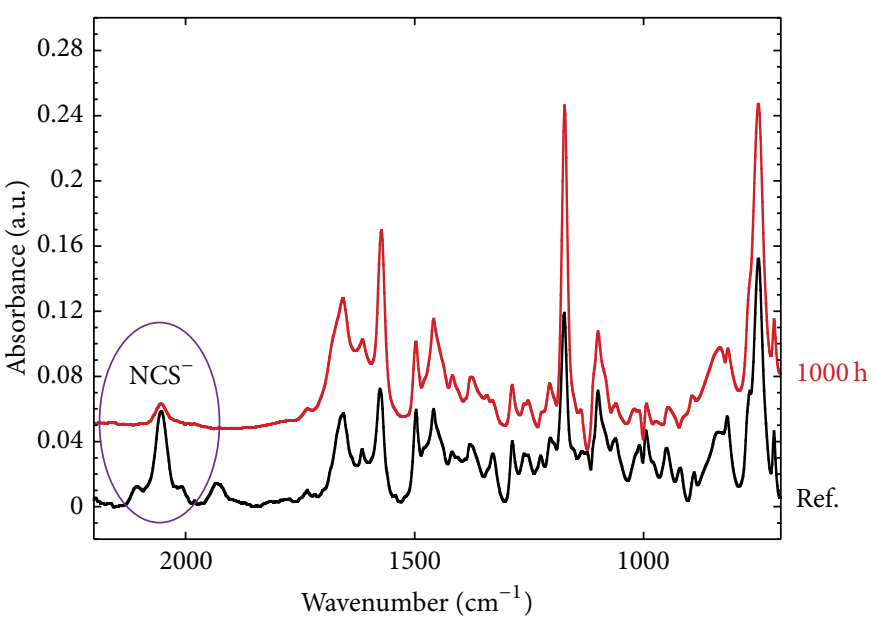

(b)

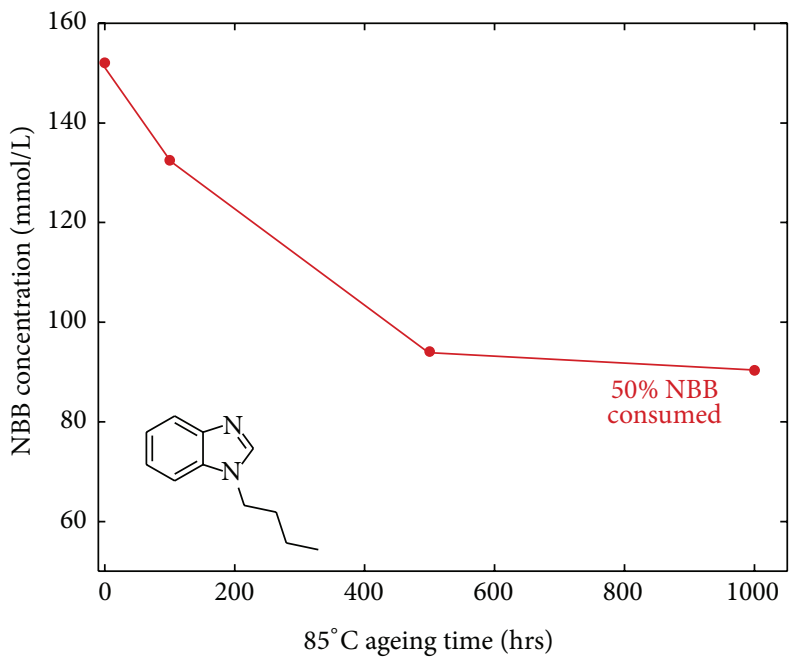

(c)

FIGURE 11: (a) Comparison of cyclic voltamperometry recorded on Pt microelectrode for MPN-based electrolyte aged in contact with $\mathrm{TiO}_{2}$ during 100, 200, and 500 hours at $85^{\circ} \mathrm{C} /$ dark. (b) ATR-FT-IR spectra comparison of MPN-based reference electrolyte before and after 1000 hours ageing at $85^{\circ} \mathrm{C} /$ dark in contact with $\mathrm{TiO}_{2}$. (c) Quantification by LC/MS of NBB concentration as a function of ageing time at $85^{\circ} \mathrm{C} /$ dark in contact with $\mathrm{TiO}_{2}$.

anchored onto $\mathrm{TiO}_{2}$. Following this hypothesis, increased stability will thus require a fast recovery of the reduced form to prevent this side reaction to occur.

The chemical/photo-(electro-)chemical durability of ruthenium polypyridyl-based sensitizers in contact with $\mathrm{TiO}_{2}$ had been questioned well before the seminal paper from Anderson et al. in 1979 [163]. The underlying effect of the nanostructuration of $\mathrm{TiO}_{2}$ on the ruthenium-complex stability was discussed [4]. The authors presented photocurrent stability over 2 months subjected to continuous visible light illumination stress with less than $10 \%$ degradation corresponding to stability over $5.10^{6}$ turnovers. Similar arguments were reported on monomeric dye without noticeable degradation [164].

These intriguing results are in relative contradiction with other reports on $c i s-\mathrm{Ru}(\mathrm{bpy})_{2}(\mathrm{SCN})_{2}$ (bpy $=2,2^{\prime}$ bipyridine) but also on trimeric ruthenium dyes [165]. The lack of structural robustness of N719 and Z907 had been reported in particular by Tributsch, Hagfeldt, and Lund. These authors became consensually alarmed on the vulnerability of the strong electron donor thiocyanate ligand which can easily exchange with electrolyte components as a result of the antibonding character of these orbitals. This ligand exchange reaction is triggered not only by light action (photolysis) but also can be activated by temperatures above $80^{\circ} \mathrm{C}$. The monodentate thiocyanate ligand can then exchange with acetonitrile or 3-methoxypropionitrile when used as a solvent (in integral or fragmented part such as $\mathrm{C} \equiv \mathrm{N}$ ), with 4-tertbutylpyridine, water residues, or even iodide [165-173]. The different exchange reactions reported are summarized in Figure 14. This reactivity of the monodentate thiocyanate ligand was explained by Grünwald and Tributsch on the basis of an incomplete reduction of the photooxidized dye by $\mathrm{I}_{3}{ }^{-} / \mathrm{I}^{-}$ redox couple in combination with a certain lack of stability 


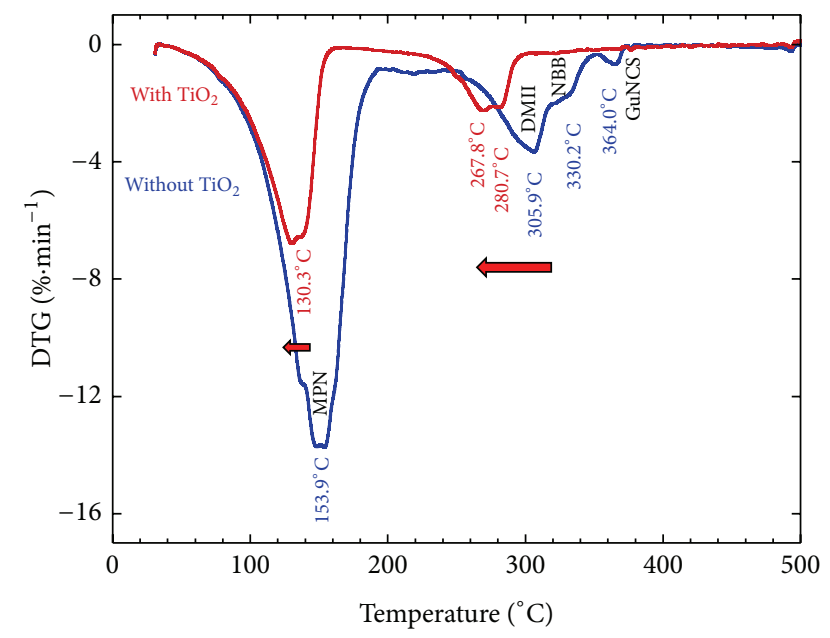

FIGURE 12: Comparison of TGA derivative curve as a function of temperature comparing the intrinsic MPN-based electrolyte stability and the same in presence of $\mathrm{TiO}_{2}$.

of the oxidized form of the complex [165]. This explanation was further confirmed by Kohle et al. who showed in solution that dye instability can also get prompted by a too low concentration of iodide, in other words when decreasing the rate constant for the dye regeneration [174]. The results provided by Lund et al. suggest again that $\mathrm{TiO}_{2}$ plays a significant catalytic activity towards this ligand exchange reaction which is accelerated by a factor of 2 .

It is also suggested that some degradation products of N719 and Z907 dyes are in equilibrium together [171] (Figure 13). It was for instance evoked in three interrelated equilibrium reactions:

$$
\begin{aligned}
& {\left[\mathrm{RuLL}^{\prime}(\mathrm{NCS})_{2}\right]+3-\mathrm{MPN} \longleftrightarrow\left[\mathrm{RuLL}^{\prime}(\mathrm{NCS})(3-\mathrm{MPN})\right]^{+}+\mathrm{NCS}^{-}} \\
& {\left[\mathrm{RuLL}^{\prime}(\mathrm{NCS})(3-\mathrm{MPN})\right]^{+}+4-\mathrm{TBP} \longleftrightarrow\left[\mathrm{RuLL}^{\prime}(\mathrm{NCS})(4-\mathrm{TBP})\right]^{+}+3-\mathrm{MPN}} \\
& {\left[\mathrm{RuLL}^{\prime}(\mathrm{NCS})_{2}\right]+4-\mathrm{TBP} \longleftrightarrow\left[\mathrm{RuLL}^{\prime}(\mathrm{NCS})(4-\mathrm{TBP})\right]^{+}+\mathrm{NCS}^{-}}
\end{aligned}
$$

The rate for this ligand exchange reaction can be lowered by a factor of 2 when including a buffer concentration of thiocyanate anions in the electrolyte (e.g., guanidinium thiocyanate) $[169,175]$. The degradation products based on 4 -TBP can be prevented by replacing this latter with N-butyl benzimidazole or the closely related benzimidazole which enhances the device stability. This can explain in part or in whole the better stability achieved with NBB (Figure 6(a)). Although such ligand exchange reactions will affect the optical MLCT (metal-to-ligand charge transfer) contribution, entailing either slight bathochromic or hypsochromic shift of absorption [132], the real implication of this in situ/in operando dye structure modification on the practical cell characteristics remains unclear. Finally, again in the work published by Grünwald and Tributsch, the authors exposed the possibility that the ruthenium hexacoordination can get fragmented, leading to the desorption of the metal core unit and the retaining of the anchoring bipyridine group attached upon $\mathrm{TiO}_{2}$ [165].

Beside these intrinsic degradation mechanisms highlighted to date, more external contributions to the cell degradation have also been exposed, namely, sealing conditions, substrate corrosion, and sealing issues. Assessment in these technical aspects is relatively complex to detail since they are rarely published. An interesting work reported by Fredin et al. aims at alarming the importance to consider the temperature of sealing as it will determine the device efficiency [176]. This work was examined by comparing N719 with the organic D5 sensitizer. The authors found that N719 appears more sensitive to thermal degradation than electrodes sensitized with the organic D5. Under temperatures lying between $120^{\circ} \mathrm{C}$ and $250^{\circ} \mathrm{C}$ for 5 minutes, the cell efficiency can vary from a maximum of $c a .4 \%$ to almost nothing when cells were sealed with an excessive sealing temperature $\left(>200^{\circ} \mathrm{C}\right)$. By using IMPS/IMVS spectroscopies, they also highlighted that the electron diffusion length, referring to the charge collection efficiency, can get as low as $10 \%$.

The encapsulation of the cells should prevent the exchange of material between the inner part of the cell and the ambient environment. It is crucial for the cell stability that the encapsulation creates a barrier against water and oxygen ingress which can be assimilated by the electrolyte and the mesoporous sensitized $\mathrm{TiO}_{2}$ layer. Conversely water has also been reported to enhance the power conversion efficiency performances of DSC based on ionic liquids [177]. The proportion of water in the cell can drastically modify the proton concentration in the electrolyte. Note that proton is a potential determining cation; in other words it tends to form specific adsorption on the surface of $\mathrm{TiO}_{2}$ leading to downward shift in energy of the Fermi level and conduction band edge [178]. A critical threshold value of water concentration to maintain high stability and improve the cell efficiency is difficult to evaluate although it is an important factor governing the device stability. One difficulty to assess this threshold value results from the inappropriateness of DSC's electrolyte towards Karl-Fischer titration because of iodine. On the other hand, this threshold value is expected to strongly depend not only on the type of dye used but also on the type of electrolyte.

Finally, the general photocatalytic properties of $\mathrm{TiO}_{2}$ should be mentioned since it could trigger the formation of hydrogen peroxide from oxygen and water, which itself can destructively oxidize organic compounds $[179,180]$. The production of $\mathrm{H}_{2} \mathrm{O}_{2}$ is initiated by the reduction of $\mathrm{O}_{2}$ from conduction band electrons in $\mathrm{TiO}_{2}$ leading to superoxide anion $\mathrm{O}_{2}{ }^{-\bullet}$ which in turn will react with water. It should also be stressed that because of the instability in nature of the superoxide anion radical, it can also directly participate in internal chemical reactions to other organic cell components [181].

Related to the sealing of the cell is the conductive substrate (transparent conducting oxide, TCO) itself which in some specific conditions can sustain a number of events leading to its conduction loss properties. The indium-doped tin oxide (ITO) layer can irreversibly lose its conductivity when voltages above $1.5 \mathrm{~V}$ are applied, needless to remind that 


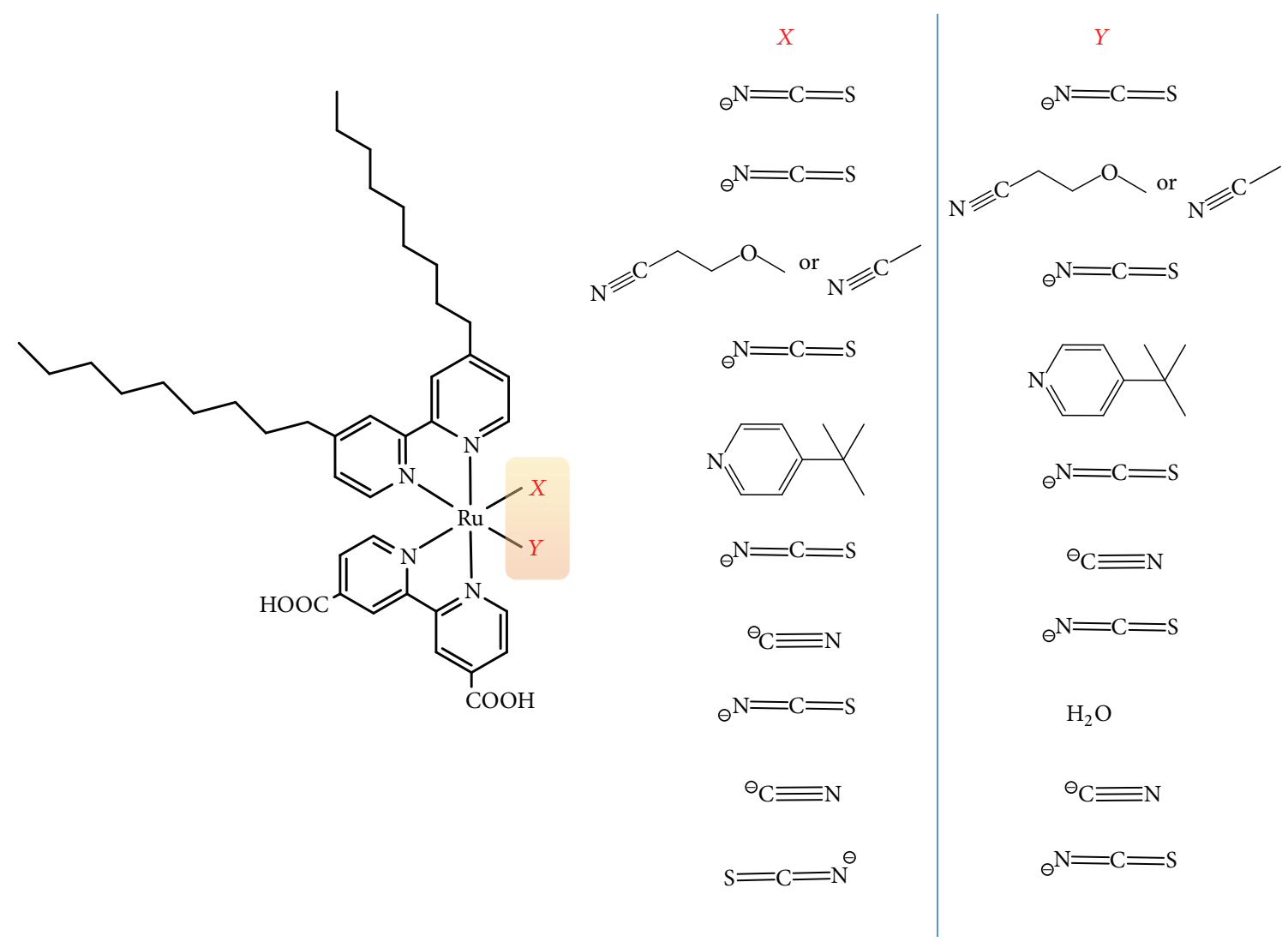

FIGURE 13: Resume of the different dye side-products characterized on either N719 or Z907Na after ageing (adapted from [172, 173]).

such voltages can be reached in series modules [182]. This may bring issues, for instance, for flexible devices for which the substrate is typically made of ITO deposited on polyethylene naphthalate (PEN) or polyethylene terephthalate (PET).

\section{Conclusive Remarks}

After being strongly questioned subsequently to the seminal publication of Graetzel et al. describing nanocrystalline dyesensitized solar cells, the macroscopic stability of DSCs is now reported in hundreds of publications. To date IEC61646 accelerated protocol is passed by a few companies although the power conversion efficiency performances are still lagging well behind the champion numbers reported by the public research laboratories. The development of stable DSCs was principally relying on beliefs and excellent intuitions from the community gathered after more than 20 years of research. We can only regret that yet very little is known as a whole about the interrelated chemical reactions responsible for the device ageing and the stress factors responsible for this degradation. Which is the most critical parameter: UV, visible light, or temperature? The experiments gathered in our group on electrolyte stability pointed out the temperature to be the most critical parameter.

In practice, stability investigation papers mainly report the evolution of the cell characteristics as a function of time.
Less often, IMVS-IMPS, EIS, and transient photovoltage/ photocurrent decay were techniques used to monitor the influence of ageing on the charge transfer kinetics and distribution and on the energy of the surface trap states in the nanocrystalline $\mathrm{TiO}_{2}$. For further improvement, not only for stable power conversion efficiency but also for prolonging significantly the lifetime of DSC to get competitive with silicon technology, there is an urgent need to establish a set of experiments and to develop techniques for careful analyses and characterization of the degradation products which are formed upon device ageing. In this area, only a very few groups are actively contributing to puzzling the complexity of dye-sensitized solar cells.

In this review, we spotted that $\mathrm{TiO}_{2}$ plays a major role in the device stability. This goes particularly against the preconceived idea that the inorganic part of the cell is the most robust compared to organic and organometallic compounds. In fact $\mathrm{TiO}_{2}$ displays a catalytic role not only for the dye degradation as it had been clearly demonstrated by the pioneering work of Lund's group but also for the electrolyte stability, in particular those based on alkyl and alkoxynitrile solvents which we are currently scrutinizing. Understanding the multifaceted and interplay chemistry of dye-sensitized solar cells and developing new materials based on such knowledge will indisputably open up significant stability breakthrough in this mystic artificial photosynthetic solar cell (Figure 14). 


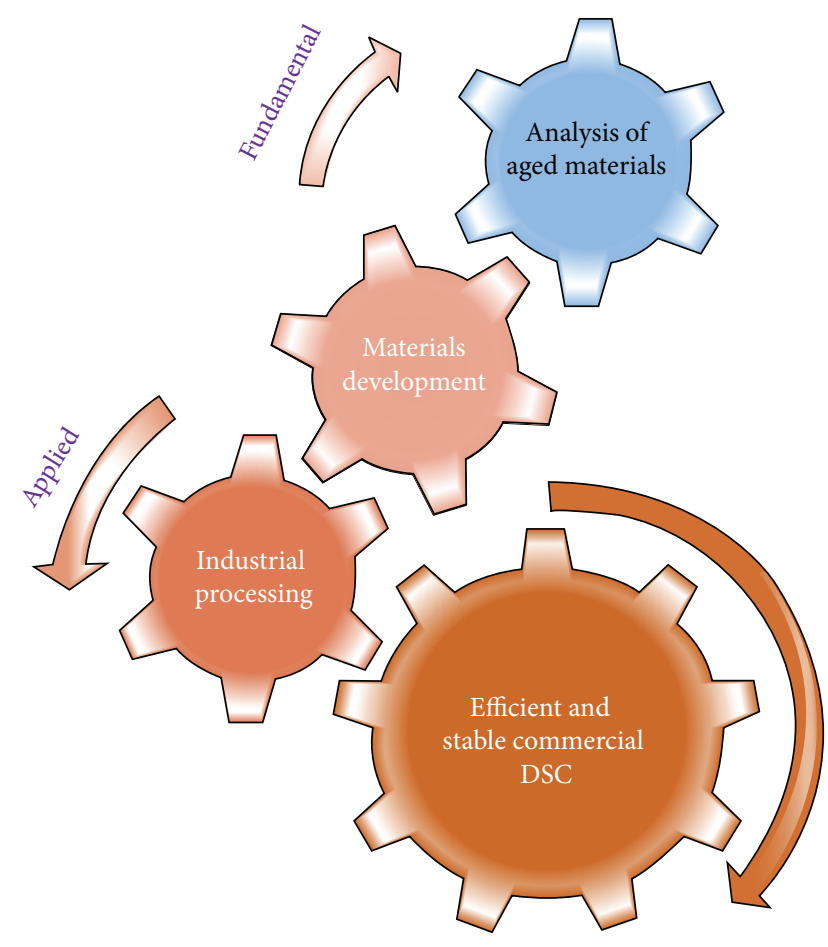

FiguRe 14

\section{Conflict of Interests}

The author declares that there is no conflict of interests regarding the publication of this paper.

\section{Acknowledgments}

The author wishes to thank the contributors involved in dyesensitized solar cell group at LRCS, Miguel Flasque, Vittoria Novelli, Iryna Sagaidak, Guillaume Huertas, Dr. Nadia Barbero, Dr. Gregory Gachot, and Dr. Albert Nguyen Van Nhien (LG2A CNRS FRE 3517). He also expresses his gratitude to Sarine Chhor (EPFL) for her contribution to butyronitrile work, Dr. Aravind Kumar Chandiran (EPFL) for his doping work, Dr. Robin Humphry-Baker (EPFL) for FT-IR analysis of aged electrolyte, Dr. Carine Davoisne (LRCS) for TEM measurements, and Mathieu Courty (LRCS) for TGA analysis. Carine Lenfant (LRCS) is acknowledged for reading the paper. The author is also indebted to the FEDER and Région Picardie for financial support of ROBUST research program.

\section{References}

[1] A. E. Becquerel, "Mémoire sur les effets électriques produits sous l'influence des rayons solaires," Comptes Rendus des Séances Hebdomadaires, vol. 9, pp. 561-567, 1839.

[2] D. M. Chapin, C. S. Fuller, and G. L. Pearson, "A new silicon p-n junction photocell for converting solar radiation into electrical power," Journal of Applied Physics, vol. 25, no. 5, pp. 676-677, 1954.

[3] D. M. Chapin, B. Ridge, C. S. Fuller, and G. L. Pearson, Solar Energy Converting Apparatus, US Patent no. 2,780,765, 1957.
[4] B. O’Regan and M. Graetzel, "Low-cost, high-efficiency solar cell based on dye-sensitized colloidal $\mathrm{TiO}_{2}$ films," Nature, vol. 353, pp. 737-740, 1991.

[5] H. W. Vogel, "On the sensitiveness of bromide of silver to the so-called chemically inactive colours," Berichte Deutsche Chemische Gesellschaft, vol. 6, p. 1320, 1873.

[6] H. Gerischer, M. E. Michel-Beyerle, F. Rebentrost, and H. Tributsch, "Sensitization of charge injection into semiconductors with large band gap," Electrochimica Acta, vol. 13, no. 6, pp. 1509-1515, 1968.

[7] H. Tributsch and M. Calvin, "Electrochemistry of excited molecules: photo-electrochemical reactions of chlorophylls," Photochemistry and Photobiology, vol. 14, no. 14, pp. 95-112, 1971.

[8] H. Tributsch, "Reaction of excited chorophyll molecules at electrodes and in photosynthesis," Photochemistry and Photobiology, vol. 16, no. 16, pp. 261-269, 1972.

[9] M. Graetzel, "Solar energy conversion by dye-sensitized photovoltaic cells," Inorganic Chemistry, vol. 44, pp. 6841-6851, 2005.

[10] M. K. Nazeeruddin, A. Kay, J. Rodicio et al., "Conversion of light to electricity by cis-X2bis $\left(2,2^{\prime}\right.$-bipyridyl- $4,4^{\prime}$-dicarboxylate) ruthenium(II) charge-transfer sensitizers (X $=\mathrm{Cl}-, \mathrm{Br}-, \mathrm{I}-, \mathrm{CN}-$, and SCN-) on nanocrystalline titanium dioxide electrodes," Journal of the American Chemical Society, vol. 115, no. 14, pp. 6382-6390, 1993.

[11] Y. Chiba, A. Islam, Y. Watanabe, R. Komiya, N. Koide, and L. Han, "Dye-sensitized solar cells with conversion efficiency of 11.1\%," Japanese Journal of Applied Physics, vol. 45, no. 25, pp. L638-L640, 2006.

[12] F. Gao, Y. Wang, D. Shi et al., "Enhance the optical absorptivity of nanocrystalline $\mathrm{TiO}_{2}$ film with high molar extinction coefficient ruthenium sensitizers for high performance dyesensitized solar cells," Journal of the American Chemical Society, vol. 130, no. 32, pp. 10720-10728, 2008.

[13] F. Gao, Y. Wang, J. Zhang et al., "A new heteroleptic ruthenium sensitizer enhances the absorptivity of mesoporous titania film for a high efficiency dye-sensitized solar cell," Chemical Communications, no. 23, pp. 2635-2637, 2008.

[14] Y. Cao, Y. Bai, Q. Yu et al., "Dye-sensitized solar cells with a high absorptivity ruthenium sensitizer featuring a 2-(hexylthio) thiophene conjugated bipyridine," Journal of Physical Chemistry C, vol. 113, no. 15, pp. 6290-6297, 2009.

[15] F. Sauvage, J.-D. Decoppet, M. Zhang et al., "Effect of sensitizer adsorption temperature on the performance of dye-sensitized solar cells," Journal of the American Chemical Society, vol. 133, no. 24, pp. 9304-9310, 2011.

[16] F. Sauvage, D. Chen, P. Comte et al., "Dye-sensitized solar cells employing a single film of mesoporous $\mathrm{TiO}_{2}$ beads achieve power conversion efficiencies over 10\%," ACS Nano, vol. 4, no. 8 , pp. 4420-4425, 2010.

[17] A. Yella, H. W. Lee, H. N. Tsao et al., "Porphyrin-sensitized solar cells with cobalt (II/III)-based redox electrolyte exceed 12 percent efficiency," Science, vol. 334, no. 6056, pp. 629-634, 2011.

[18] S. Mathew, A. Yella, P. Gao et al., "Dye-sensitized solar cells with $13 \%$ efficiency achieved through the molecular engineering of porphyrin sensitizers," Nature Chemistry, vol. 6, no. 3, pp. 242247, 2014.

[19] J. Burschka, N. Pellet, S.-J. Moon et al., "Sequential deposition as a route to high-performance perovskite-sensitized solar cells," Nature, vol. 499, no. 7458, pp. 316-319, 2013.

[20] S. I. Soek, "Efficieny enhancement in inorganic/organic hybrid solar cells," Hybrid and Organic Photovoltaics, p. I16, 2014. 
[21] M. Matsumura, S. Matsudaira, H. Tsubomura, M. Takata, and H. Yanagida, "Dye sensitization and surface structures of semiconductor electrodes," Industrial \& Engineering Chemistry Product Research and Development, vol. 19, no. 3, pp. 415-421, 1980.

[22] C. Magne, S. Cassaignon, G. Lancel, and T. Pauporté, "Brookite $\mathrm{TiO}_{2}$ nanoparticle films for dye-sensitized solar cells," ChemPhysChem, vol. 12, no. 13, pp. 2461-2467, 2011.

[23] H.-J. Koo, J. Park, B. Yoo, K. Yoo, K. Kim, and N.-G. Park, "Sizedependent scattering efficiency in dye-sensitized solar cell," Inorganica Chimica Acta, vol. 361, no. 3, pp. 677-683, 2008.

[24] K. Tennakone, G. R. R. A. Kumara, I. R. M. Kottegoda, and V. P. S. Perera, "An efficient dye-sensitized photoelectrochemical solar cell made from oxides of tin and zinc," Chemical Communications, no. 1, pp. 15-16, 1999.

[25] M. Quintana, T. Edvinsson, A. Hagfeldt, and G. Boschloo, "Comparison of dye-sensitized $\mathrm{ZnO}$ and $\mathrm{TiO}_{2}$ solar cells: Studies of charge transport and carrier lifetime," Journal of Physical Chemistry C, vol. 111, no. 2, pp. 1035-1041, 2007.

[26] J. Elias, M. Parlinska-Wojtan, R. Erni et al., "Passing the limit of electrodeposition: "gas template" $\mathrm{H}_{2}$ nanobubbles for growing highly crystalline nanoporous $\mathrm{ZnO}$," Nano Energy, vol. 1, no. 5, pp. 742-750, 2012.

[27] J. Fan, Y. Hao, A. Cabot, E. M. J. Johansson, G. Boschloo, and A. Hagfeldt, "Cobalt(II/III) redox electrolyte in $\mathrm{ZnO}$ nanowirebased dye-sensitized solar cells," ACS Applied Materials and Interfaces, vol. 5, no. 6, pp. 1902-1906, 2013.

[28] R. L. Willis, C. Olson, B. O’Regan, T. Lutz, J. Nelson, and J. R. Durrant, "Electron dynamics in nanocrystalline $\mathrm{ZnO}$ and $\mathrm{TiO}_{2}$ films probed by potential step chronoamperometry and transient absorption spectroscopy," The Journal of Physical Chemistry B, vol. 106, no. 31, pp. 7605-7613, 2002.

[29] K. Keis, J. Lindgren, S.-E. Lindquist, and A. Hagfeldt, "Studies of the adsorption process of Ru complexes in nanoporous $\mathrm{ZnO}$ electrodes," Langmuir, vol. 16, no. 10, pp. 4688-4694, 2000.

[30] B. Liu and H. C. Zeng, "Hydrothermal synthesis of $\mathrm{ZnO}$ nanorods in the diameter regime of $50 \mathrm{~nm}$," Journal of the American Chemical Society, vol. 125, no. 15, pp. 4430-4431, 2003.

[31] C. Bauer, G. Boschloo, E. Mukhtar, and A. Hagfeldt, "Electron injection and recombination in $\mathrm{Ru}(\mathrm{dcbpy}) 2$ (NCS)2 sensitized nanostructured Zno," Journal of Physical Chemistry B, vol. 105, no. 24, pp. 5585-5588, 2001.

[32] P. Tiwana, P. Docampo, M. B. Johnston, H. J. Snaith, and L. M. Herz, "Electron mobility and injection dynamics in mesoporous $\mathrm{ZnO}, \mathrm{SnO}_{2}$, and $\mathrm{TiO}_{2}$ films used in dye-sensitized solar cells," ACS Nano, vol. 5, no. 6, pp. 5158-5166, 2011.

[33] C. Y. Jiang, X. W. Sun, G. Q. Lo, D. L. Kwong, and J. X. Wang, "Improved dye-sensitized solar cells with a $\mathrm{ZnO}$-nanoflower photoanode," Applied Physics Letters, vol. 90, no. 26, Article ID 263501, 2007.

[34] Q. Zhang, C. S. Dandeneau, X. Zhou, and C. Cao, "ZnO nanostructures for dye-sensitized solar cells," Advanced Materials, vol. 21, no. 41, pp. 4087-4108, 2009.

[35] K. Westermark, H. Rensmo, H. Siegbahn et al., "PES studies of $\mathrm{Ru}\left(\mathrm{dcbpyH}_{2}\right)_{2}(\mathrm{NCS})_{2}$ adsorption on nanostructured $\mathrm{ZnO}$ for solar cell applications," The Journal of Physical Chemistry B, vol. 106, no. 39, pp. 10102-10107, 2002.

[36] R. Schoölin, M. Quintana, E. M. J. Johansson et al., "Preventing dye aggregation on $\mathrm{ZnO}$ by adding water in the dyesensitization process," Journal of Physical Chemistry C, vol. 115, no. 39, pp. 19274-19279, 2011.
[37] Q. Zhang, T. P. Chou, B. Russo, S. A. Jenekhe, and G. Cao, "Aggregation of $\mathrm{ZnO}$ nanocrystallites for high conversion efficiency in dye-sensitized solar cells," Angewandte Chemie, vol. 120, no. 13, pp. 2436-2440, 2008.

[38] Y. Shi, C. Zhu, L. Wang et al., "Ultrarapid sonochemical synthesis of $\mathrm{ZnO}$ hierarchical structures: from fundamental research to high efficiencies up to $6.42 \%$ for quasi-solid dyesensitized solar cells," Chemistry of Materials, vol. 25, no. 6, pp. 1000-1012, 2013.

[39] A. B. F. Martinson, J. W. Elam, J. T. Hupp, and M. J. Pellin, “ZnO nanotube based dye-sensitized solar cells," Nano Letters, vol. 7, no. 8, pp. 2183-2187, 2007.

[40] H. Rensmo, K. Keis, H. Lindström et al., "High light-to-energy conversion efficiencies for solar cells based on nanostructured ZnO electrodes," Journal of Physical Chemistry B, vol. 101, no. 14, pp. 2598-2601, 1997.

[41] M. Law, L. E. Greene, J. C. Johnson, R. Saykally, and P. Yang, "Nanowire dye-sensitized solar cells," Nature Materials, vol. 4, no. 6, pp. 455-459, 2005.

[42] J. B. Baxter and E. S. Aydil, "Nanowire-based dye-sensitized solar cells," Applied Physics Letters, vol. 86, Article ID 053114, 2005.

[43] A. K. Chandiran, M. Abdi-Jalebi, M. K. Nazeeruddin, and M. Grätzel, "Analysis of electron transfer properties of $\mathrm{ZnO}$ and $\mathrm{TiO}_{2}$ photoanodes for dye-sensitized solar cells," ACS Nano, vol. 8, no. 3, pp. 2261-2268, 2014.

[44] S. Ferrere, A. Zaban, and B. A. Gregg, "Dye sensitization of nanocrystalline tin oxide by perylene derivatives," The Journal of Physical Chemistry B, vol. 101, no. 23, pp. 4490-4493, 1997.

[45] A. Kay and M. Grätzel, "Dye-Sensitized core-shell nanocrystals: Improved efficiency of mesoporous tin oxide electrodes coated with a thin layer of an insulating oxide," Chemistry of Materials, vol. 14, no. 7, pp. 2930-2935, 2002.

[46] E. N. Kumar, R. Jose, P. S. Archana, C. Vijila, M. M. Yusoff, and S. Ramakrishna, "High performance dye-sensitized solar cells with record open circuit voltage using tin oxide nanoflowers developed by electrospinning," Energy and Environmental Science, vol. 5, no. 1, pp. 5401-5407, 2012.

[47] Y. P. Y. P. Ariyasinghe, T. R. C. K. Wijayarathna, I. G. C. K. Kumara et al., "Efficient passivation of $\mathrm{SnO}_{2}$ nano crystallites by Indoline D-149 via dual chelation," Journal of Photochemistry and Photobiology A: Chemistry, vol. 217, no. 1, pp. 249-252, 2011.

[48] H. J. Snaith and C. Ducati, " $\mathrm{SnO}_{2}$-Based dye-sensitized hybrid solar cells exhibiting near unity absorbed photon-to-electron conversion efficiency," Nano Letters, vol. 10, no. 4, pp. 1259-1265, 2010.

[49] J. Z. Ou, R. A. Rani, M.-H. Ham et al., "Elevated temperature anodized $\mathrm{Nb}_{2} \mathrm{O}_{5}$ : a photoanode material with exceptionally large photoconversion efficiencies," ACS Nano, vol. 6, no. 5, pp. 4045-4053, 2012.

[50] K. Sayama, H. Sugihara, and H. Arakawa, "Photoelectrochemical properties of a porous $\mathrm{Nb}_{2} \mathrm{O}_{5}$ electrode sensitized by a ruthenium dye," Chemistry of Materials, vol. 10, no. 12, pp. 38253832, 1998.

[51] R. Ghosh, M. K. Brennaman, T. Uher et al., "Nanoforest $\mathrm{Nb}_{2} \mathrm{O}_{5}$ photoanodes for dye-sensitized solar cells by pulsed laser deposition," ACS Applied Materials \& Interfaces, vol. 3, no. 10, pp. 3929-3935, 2011.

[52] A. le Viet, R. Jose, M. V. Reddy, B. V. R. Chowdari, and S. Ramakrishna, " $\mathrm{Nb}_{2} \mathrm{O}_{5}$ photoelectrodes for dye-sensitized solar cells: choice of the polymorph," Journal of Physical Chemistry C, vol. 114, no. 49, pp. 21795-21800, 2010. 
[53] S. G. Chen, S. Chappel, Y. Diamant, and A. Zaban, "Preparation of $\mathrm{Nb}_{2} \mathrm{O}_{5}$ coated $\mathrm{TiO}_{2}$ nanoporous electrodes and their application in dye-sensitized solar cells," Chemistry of Materials, vol. 13, no. 12, pp. 4629-4634, 2001.

[54] K. Sayama, H. Suguhara, and H. Arakawa, "Photoelectrochemical properties of a porous $\mathrm{Nb}_{2} \mathrm{O}_{5}$ electrode sensitized by a ruthenium dye," Chemistry of Materials, vol. 10, no. 12, pp. 38253832, 1998.

[55] P. Guo and M. A. Aegerter, "RU(II) sensitized $\mathrm{Nb}_{2} \mathrm{O}_{5}$ solar cell made by the sol-gel process," Thin Solid Films, vol. 351, no. 1-2, pp. 290-294, 1999.

[56] K. Hara, T. Horiguchi, T. Kinoshita, K. Sayama, H. Sugihara, and H. Arakawa, "Highly efficient photon-to-electron conversion with mercurochrome-sensitized nanoporous oxide semiconductor solar cells," Solar Energy Materials and Solar Cells, vol. 64, no. 2, pp. 115-134, 2000.

[57] S. Burnside, J.-E. Moser, K. Brooks, M. Grätzel, and D. Cahen, "Nanocrystalline mesoporous strontium titanate as photoelectrode material for photosensitized solar devices: increasing photovoltage through flatband potential engineering," Journal of Physical Chemistry B, vol. 103, no. 43, pp. 9328-9332, 1999.

[58] R. Dabestani, A. J. Bard, A. Campion et al., "Sensitization of titanium dioxide and strontium titanate electrodes by ruthenium(II) tris $\left(2,2^{\prime}\right.$-bipyridine- $4,4^{\prime}$-dicarboxylic acid) and zinc tetrakis(4-carboxyphenyl)porphyrin: an evaluation of sensitization efficiency for component photoelectrodes in a multipanel device," The Journal of Physical Chemistry, vol. 92, no. 7, pp. 1872-1878, 1988.

[59] S. Yang, H. Kou, J. Wang, H. Xue, and H. Han, “Tunability of the band energetics of nanostructured $\mathrm{SrTiO}_{3}$ electrodes for dyesensitized solar cells," The Journal of Physical Chemistry C, vol. 114, no. 9, pp. 4245-4249, 2010.

[60] S. S. Shin, J. S. Kim, J. H. Suk et al., "Improved quantum efficiency of highly efficient perovskite $\mathrm{BaSnO}_{3}$-based dyesensitized solar cells," ACS Nano, vol. 7, no. 2, pp. 1027-1035, 2013.

[61] B. Tan, E. Toman, Y. Li, and Y. Wu, "Zinc stannate $\left(\mathrm{Zn}_{2} \mathrm{SnO}_{4}\right)$ dye-sensitized solar cells," Journal of the American Chemical Society, vol. 129, no. 14, pp. 4162-4163, 2007.

[62] S.-H. Choi, D. Hwang, D.-Y. Kim et al., "Amorphous zinc stannate $\left(\mathrm{Zn}_{2} \mathrm{SnO}_{4}\right)$ nanofibers networks as photoelectrodes for organic dye-sensitized solar cells," Advanced Functional Materials, vol. 23, no. 25, pp. 3146-3155, 2013.

[63] K. Zhu, N. R. Neale, A. Miedaner, and A. J. Frank, "Enhanced charge-collection efficiencies and light scattering in dyesensitized solar cells using oriented $\mathrm{TiO}_{2}$ nanotubes arrays," Nano Letters, vol. 7, no. 1, pp. 69-74, 2007.

[64] H. E. Prakasam, K. Shankar, M. Paulose, O. K. Varghese, and C. A. Grimes, "A new benchmark for $\mathrm{TiO}_{2}$ nanotube array growth by anodization," Journal of Physical Chemistry C, vol. 111, no. 20, pp. 7235-7241, 2007.

[65] J. R. Jennings, A. Ghicov, L. M. Peter, P. Schmuki, and A. B. Walker, "Dye-sensitized solar cells based on oriented $\mathrm{TiO}_{2}$ nanotube arrays: transport, trapping, and transfer of electrons," Journal of the American Chemical Society, vol. 130, no. 40, pp. 13364-13372, 2008.

[66] D. Kim, A. Ghicov, S. P. Albu, and P. Schmuki, "Bamboo-type $\mathrm{TiO}_{2}$ nanotubes: Improved conversion efficiency in dyesensitized solar cells," Journal of the American Chemical Society, vol. 130, no. 49, pp. 16454-16455, 2008.
[67] G. K. Mor, S. Kim, M. Paulose et al., "Visible to near-infrared light harvesting in $\mathrm{TiO}_{2}$ nanotube array-P3HT based heterojunction solar cells," Nano Letters, vol. 9, no. 12, pp. 4250-4257, 2009.

[68] F. Sauvage, F. Di Fonzo, A. Li Bassi et al., "Hierarchical $\mathrm{TiO}_{2}$ photoanode for dye-sensitized solar cells," Nano Letters, vol. 10, no. 7, pp. 2562-2567, 2010.

[69] X. Feng, K. Zhu, A. J. Frank, C. A. Grimes, and T. E. Mallouk, "Rapid charge transport in dye-sensitized solar cells made from vertically aligned single-crystal rutile $\mathrm{TiO}_{2}$ nanowires," Angewandte Chemie - International Edition, vol. 51, no. 11, pp. 2727-2730, 2012.

[70] K. Zhu, S. R. Jang, and A. J. Frank, "Impact of high charge-collection efficiencies and dark energy-loss processes on transport, recombination, and photovoltaic properties of dyesensitized solar cells," The Journal of Physical Chemistry Letters, vol. 2, no. 9, pp. 1070-1076, 2011.

[71] K. Zhu, T. B. Vinzant, N. R. Neale, and A. J. Frank, "Removing structural disorder from oriented $\mathrm{TiO}_{2}$ nanotube arrays: reducing the dimensionality of transport and recombination in dyesensitized solar cells," Nano Letters, vol. 7, no. 12, pp. 3739-3746, 2007.

[72] D. H. Chen, F. Z. Huang, Y. B. Cheng, and R. A. Caruso, "Mesoporous anatase $\mathrm{TiO}_{2}$ beads with high surface areas and controllable pore sizes: a superior candidate for highperformance dye-sensitized solar cells," Advanced Materials, vol. 21, pp. 2206-2210, 2009.

[73] D. H. Chen, L. Cao, F. Z. Huang, P. Imperia, Y. B. Cheng, and R. A. Caruso, "Synthesis of monodisperse mesoporous titania beads with controllable diameter, high surface areas, and variable pore diameters (14-23 nm)," Journal of the American Chemical Society, vol. 132, no. 12, pp. 4438-4444, 2010.

[74] A. R. Pascoe, D. Chen, F. Huang et al., "Charge transport and recombination in dye-sensitized solar cells on plastic substrates," The Journal of Physical Chemistry C, vol. 118, no. 28, pp. 15154-15161, 2014.

[75] E. M. Hopper, F. Sauvage, A. K. Chandiran, M. Grätzel, K. R. Poeppelmeier, and T. O. Mason, "Electrical properties of Nb-, Ga-, and Y-substituted nanocrystalline anatase $\mathrm{TiO}_{2}$ prepared by hydrothermal synthesis," Journal of the American Ceramic Society, vol. 95, no. 10, pp. 3192-3196, 2012.

[76] X. Zhang, F. Liu, Q.-L. Huang, G. Zhou, and Z.-S. Wang, "Dyesensitized $\mathrm{W}$-doped $\mathrm{TiO}_{2}$ solar cells with a tunable conduction band and suppressed charge recombination," The Journal of Physical Chemistry C, vol. 115, no. 25, pp. 12665-12671, 2011.

[77] B. Mei, M. D. Sánchez, T. Reinecke, S. Kaluza, W. Xia, and M. Muhler, "The synthesis of Nb-doped $\mathrm{TiO}_{2}$ nanoparticles by spray drying: an efficient and scalable method," Journal of Materials Chemistry, vol. 21, no. 32, pp. 11781-11790, 2011.

[78] N. Tsvetkov, L. Larina, O. Shevaleevskiy, and B. T. Ahn, "Effect of $\mathrm{Nb}$ doping of $\mathrm{TiO}_{2}$ electrode on charge transport in dyesensitized solar cells," Journal of the Electrochemical Society, vol. 158, no. 11, pp. B1281-B1285, 2011.

[79] S. G. Kim, M. J. Ju, I. T. Choi et al., "Nb-doped $\mathrm{TiO}_{2}$ nanoparticles for organic dye-sensitized solar cells," RSC Advances, vol. 3, no. 37, pp. 16380-16386, 2013.

[80] A. K. Chandiran, F. Sauvage, M. Casas-Cabanas, P. Comte, S. M. Zakeeruddin, and M. Graetzel, "Doping a $\mathrm{TiO}_{2}$ photoanode with $\mathrm{Nb}^{5+}$ to enhance transparency and charge collection efficiency in dye-sensitized solar cells," Journal of Physical Chemistry C, vol. 114, no. 37, pp. 15849-15856, 2010. 
[81] R. Ghosh, Y. Hara, L. Alibabaei et al., "Increasing photocurrents in dye sensitized solar cells with tantalum-doped titanium oxide photoanodes obtained by laser ablation," ACS Applied Materials and Interfaces, vol. 4, no. 9, pp. 4566-4570, 2012.

[82] X. Zhang, S. T. Wang, and Z. S. Wang, "Effect of metal-doping in $\mathrm{TiO}_{2}$ on fill factor of dye-sensitized solar cells," Applied Physics Letters, vol. 99, Article ID 113503, 2011.

[83] Y. Xie, N. Huang, S. You et al., "Improved performance of dye-sensitized solar cells by trace amount Cr-doped $\mathrm{TiO}_{2}$ photoelectrodes," Journal of Power Sources, vol. 224, pp. 168-173, 2013.

[84] N. A. Kyeremateng, V. Hornebecq, H. Martinez, P. Knauth, and T. Djenizian, "Electrochemical fabrication and properties of highly ordered Fe-doped $\mathrm{TiO}_{2}$ nanotubes," ChemPhysChem, vol. 13, no. 16, pp. 3707-3713, 2012.

[85] A. Latini, C. Cavallo, F. K. Aldibaja et al., "Efficiency improvement of DSSC photoanode by scandium doping of mesoporous titania beads," The Journal of Physical Chemistry C, vol. 117, no. 48, pp. 25276-25289, 2013.

[86] M. Khana and W. Cao, "Preparation of Y-doped $\mathrm{TiO}_{2}$ by hydrothermal method and investigation of its visible light photocatalytic activity by the degradation of methylene blue," Journal of Molecular Catalysis A: Chemical, vol. 376, pp. 71-77, 2013.

[87] A. K. Chandiran, F. Sauvage, L. Etgar, and M. Graetzel, "Ga ${ }^{3+}$ and $\mathrm{Y}^{3+}$ cationic substitution in mesoporous $\mathrm{TiO}_{2}$ photoanodes for photovoltaic applications," The Journal of Physical Chemistry C, vol. 115, no. 18, pp. 9232-9240, 2011.

[88] Y. Duan, N. Fu, Q. Liu et al., "Sn-doped $\mathrm{TiO}_{2}$ photoanode for dye-sensitized solar cells," The Journal of Physical Chemistry $C$, vol. 116, no. 16, pp. 8888-8893, 2012.

[89] J. Zhang, W. Peng, Z. Chen, H. Chen, and L. Han, "Effect of cerium doping in the $\mathrm{TiO}_{2}$ photoanode on the electron transport of dye-sensitized solar cells," Journal of Physical Chemistry C, vol. 116, no. 36, pp. 19182-19190, 2012.

[90] H. J. Snaith, "Estimating the maximum attainable efficiency in dye-sensitized solar cells," Advanced Functional Materials, vol. 20, no. 1, pp. 13-19, 2010.

[91] Z. Wang, K. Sayama, and H. Sugihara, "Efficient eosin Y dyesensitized solar cell containing $\mathrm{Br}^{-} / \mathrm{Br}_{3}^{-}$electrolyte," The Journal of Physical Chemistry B, vol. 109, no. 47, pp. 22449-22455, 2005.

[92] C. Teng, X. Yang, C. Yuan et al., “Two novel carbazole dyes for dye-sensitized solar cells with open-circuit voltages up to $1 \mathrm{v}$ based on $\mathrm{Br}^{-} / \mathrm{Br}_{3}^{-}$electrolytes," Organic Letters, vol. 11, no. 23, pp. 5542-5545, 2009.

[93] C. Teng, X. Yang, S. Li et al., "Tuning the HOMO energy levels of organic dyes for dye-sensitized solar cells based on Br-/Br3electrolytes," Chemistry - A European Journal, vol. 16, no. 44, pp. 13127-13138, 2010.

[94] L. Li, X. Yang, J. Gao et al., "Highly efficient CdS quantum dot-sensitized solar cells based on a modified polysulfide electrolyte," Journal of the American Chemical Society, vol. 133, no. 22, pp. 8458-8460, 2011.

[95] M. Wang, N. Chamberland, L. Breau et al., "An organic redox electrolyte to rival triiodide/iodide in dye-sensitized solar cells," Nature Chemistry, vol. 2, no. 5, pp. 385-389, 2010.

[96] D. Li, H. Li, Y. Luo et al., "Non-corrosive, non-absorbing organic redox couple for dye-sensitized solar cells," Advanced Functional Materials, vol. 20, no. 19, pp. 3358-3365, 2010.
[97] M. Cheng, X. Yang, S. Li, X. Wang, and L. Sun, "Efficient dyesensitized solar cells based on an iodine-free electrolyte using Lcysteine/L-cystine as a redox couple," Energy and Environmental Science, vol. 5, no. 4, pp. 6290-6293, 2012.

[98] H. Nusbaumer, Alternative redox systems for the dye-sensitized solar cell [Ph.D. thesis], EPFL, Lausanne, Switzerland, 2004.

[99] A. Yella, H.-W. Lee, H. N. Tsao et al., "Porphyrin-sensitized solar cells with cobalt (II/III)-based redox electrolyte exceed 12 percent efficiency," Science, vol. 334, no. 6056, pp. 629-634, 2011.

[100] S. M. Feldt, G. Wang, G. Boschloo, and A. Hagfeldt, "Effects of driving forces for recombination and regeneration on the photovoltaic performance of dye-sensitized solar cells using cobalt polypyridine redox couples," The Journal of Physical Chemistry C, vol. 115, no. 43, pp. 21500-21507, 2011.

[101] J.-H. Yum, E. Baranoff, F. Kessler et al., "A cobalt complex redox shuttle for dye-sensitized solar cells with high open-circuit potentials," Nature Communications, vol. 3, article 631, 2012.

[102] S. M. Feldt, E. A. Gibson, E. Gabrielsson, L. Sun, G. Boschloo, and A. Hagfeldt, "Design of organic dyes and cobalt polypyridine redox mediators for high-efficiency dye-sensitized solar cells," Journal of the American Chemical Society, vol. 132, no. 46, pp. 16714-16724, 2010.

[103] M. Xu, M. Zhang, M. Pastore, R. Li, F. De Angelis, and P. Wang, "Joint electrical, photophysical and computational studies on D- $\pi$-A dye sensitized solar cells: The impacts of dithiophene rigidification," Chemical Science, vol. 3, no. 4, pp. 976-983, 2012.

[104] Y. Bai, Q. Yu, N. Cai, Y. Wang, M. Zhang, and P. Wang, "Highefficiency organic dye-sensitized mesoscopic solar cells with a copper redox shuttle," Chemical Communications, vol. 47, no. 15, pp. 4376-4378, 2011.

[105] T. Daeneke, T.-H. Kwon, A. B. Holmes, N. W. Duffy, U. Bach, and L. Spiccia, "High-efficiency dye-sensitized solar cells with ferrocene-based electrolytes," Nature Chemistry, vol. 3, no. 3, pp. 211-215, 2011.

[106] T. C. Li, A. M. Spokoyny, C. She et al., "Ni(III)/(IV) Bis(dicarbollide) as a fast, noncorrosive redox shuttle for dyesensitized solar cells," Journal of the American Chemical Society, vol. 132, no. 13, pp. 4580-4582, 2010.

[107] Z. Zhang, P. Chen, T. N. Murakami, S. M. Zakeeruddin, and M. Graetzel, “The 2,2,6,6-tetramethyl-1-piperidinyloxy radical: an efficient, iodine- free redox mediator for dye-sensitized solar cells," Advanced Functional Materials, vol. 18, no. 2, pp. 341-346, 2008.

[108] K. Kalyanasundaram, K. Nazeeruddin, and M. K. Nazeeruddin, "Tuning of the CT excited state and validity of the energy gap law in mixed ligand complexes of $\mathrm{Ru}(\mathrm{II})$ containing $4,4^{\prime}$ dicarboxy-2,2'-bipyridine," Chemical Physics Letters, vol. 193, no. 4, pp. 292-297, 1992.

[109] F. de Angelis, S. Fantacci, A. Selloni, M. Grätzel, and M. K. Nazeeruddin, "Influence of the sensitizer adsorption mode on the open-circuit potential of dye-sensitized solar cells," Nano Letters, vol. 7, no. 10, pp. 3189-3195, 2007.

[110] P. Wang, S. M. Zakeeruddin, J. E. Moser, M. K. Nazeeruddin, T. Sekiguchi, and M. Grätzel, "A stable quasi-solid-state dyesensitized solar cell with an amphiphilic ruthenium sensitizer and polymer gel electrolyte," Nature Materials, vol. 2, pp. 402407, 2003.

[111] J. E. Kroeze, N. Hirata, S. Koops et al., "Alkyl chain barriers for kinetic optimization in dye-sensitized solar cells," Journal of the American Chemical Society, vol. 128, no. 50, pp. 16376-16383, 2006. 
[112] C. Y. Chen, J. G. Chen, S. J. Wu, J. Y. Li, C. G. Wu, and K. C. Ho, "Multifunctionalized ruthenium-based supersensitizers for highly efficient dye-sensitized solar cells," Angewandte Chemie International Edition, vol. 47, no. 38, pp. 7342-7345, 2008.

[113] M. K. Nazeeruddin, Q. Wang, L. Cevey et al., "DFT-INDO/S modeling of new high molar extinction coefficient chargetransfer sensitizers for solar cell applications," Inorganic Chemistry, vol. 45, no. 2, pp. 787-797, 2006.

[114] Y. Cao, Y. Bai, Q. Yu et al., "Dye-sensitized solar cells with a high absorptivity ruthenium sensitizer featuring a 2(hexylthio)thiophene conjugated bipyridine," The Journal of Physical Chemistry C, vol. 113, no. 15, pp. 6290-6297, 2009.

[115] C.-Y. Chen, M. Wang, J.-Y. Li et al., "Highly efficient lightharvesting ruthenium sensitizer for thin-film dye-sensitized solar cells," ACS Nano, vol. 3, no. 10, pp. 3103-3109, 2009.

[116] M. K. Nazeeruddin, P. Péchy, T. Renouard et al., "Engineering of efficient panchromatic sensitizers for nanocrystalline $\mathrm{TiO}_{2}-$ based solar cells," Journal of the American Chemical Society, vol. 123, no. 8, pp. 1613-1624, 2001.

[117] M. Grätzel, "Corrigendum to "Conversion of sunlight to electric power by nanocrystalline dye-sensitized solar cells" [J. Photochem. Photobiol. A: Chem. 164 (2004) 3-14]," Journal of Photochemistry and Photobiology A, vol. 168, no. 3, p. 235, 2004.

[118] A. Abbotto, F. Sauvage, C. Barolo et al., "Panchromatic ruthenium sensitizer based on electron-rich heteroarylvinylene $\pi$ conjugated quaterpyridine for dye-sensitized solar cells," Dalton Transactions, vol. 40, no. 1, pp. 234-242, 2011.

[119] S. H. Wadman, J. M. Kroon, K. Bakker et al., "Cyclometalated ruthenium complexes for sensitizing nanocrystalline $\mathrm{TiO}_{2}$ solar cells," Chemical Communications, no. 19, pp. 1907-1909, 2007.

[120] T. Bessho, E. Yoneda, J.-H. Yum et al., "New paradigm in molecular engineering of sensitizers for solar cell applications," Journal of the American Chemical Society, vol. 131, no. 16, pp. 5930-5934, 2009.

[121] P. G. Bomben, T. J. Gordon, E. Schott, and C. P. Berlinguette, "A trisheteroleptic cyclometalated RuII sensitizer that enables high power output in a dye-sensitized solar cell," Angewandte Chemie-International Edition, vol. 50, no. 45, pp. 10682-10685, 2011.

[122] C.-C. Chou, K.-L. Wu, Y. Chi et al., "Ruthenium(II) sensitizers with heteroleptic tridentate chelates for dye-sensitized solar cells," Angewandte Chemie-International Edition, vol. 50, no. 9, pp. 2054-2058, 2011.

[123] K. Hara, M. Kurashige, Y. Dan-Oh et al., "Design of new coumarin dyes having thiophene moieties for highly efficient organicdye-sensitized solar cells," New Journal of Chemistry, vol. 27, no. 5, pp. 783-785, 2003.

[124] N. A. Ludin, A. M. Al-Alwani Mahmoud, A. Bakar Mohamad, A. A. H. Kadhum, K. Sopian, and N. S. Abdul Karim, "Review on the development of natural dye photosensitizer for dyesensitized solar cells," Renewable and Sustainable Energy Reviews, vol. 31, pp. 386-396, 2014.

[125] D. Joly, L. Pelleja, S. Narbey et al., "A robust organic dye for dye sensitized solar cells based on iodine/iodide electrolytes combining high efficiency and outstanding stability," Scientific Reports, vol. 4, article 4033, 2014.

[126] W. Zeng, Y. Cao, Y. Bai et al., "Efficient dye-sensitized solar cells with an organic photosensitizer featuring orderly conjugated ethylenedioxythiophene and dithienosilole blocks," Chemistry of Materials, vol. 22, no. 5, pp. 1915-1925, 2010.

[127] Z.-S. Wang, Y. Cui, K. Hara, Y. Dan-Oh, C. Kasada, and A. Shinpo, "A high-light-harvesting-efficiency coumarin dye for stable dye-sensitized solar cells," Advanced Materials, vol. 19, no. 8, pp. 1138-1141, 2007.

[128] S. Kuster, F. Sauvage, M. K. Nazeeruddin, M. Grätzel, F. A. Nüesch, and T. Geiger, "Unsymmetrical squaraine dimer with an extended $\pi$-electron framework: an approach in harvesting near infra-red photons for energy conversion," Dyes and Pigments, vol. 87, no. 1, pp. 30-38, 2010.

[129] S. Martiniani, A. Y. Anderson, C. Law, B. C. O'Regan, and C. Barolo, "New insight into the regeneration kinetics of organic dye sensitised solar cells," Chemical Communications, vol. 48, no. 18, pp. 2406-2408, 2012.

[130] M. K. Nazeeruddin, R. Humphry-Baker, M. Grätzel et al., "Efficient Near-IR sensitization of nanocrystalline $\mathrm{TiO}_{2}$ films by zinc and aluminum phthalocyanines," Journal of Porphyrins and Phthalocyanines, vol. 3, no. 3, pp. 230-237, 1999.

[131] S. Ahmad, E. Guillén, L. Kavan, M. Grätzel, and M. K. Nazeeruddin, "Metal free sensitizer and catalyst for dye sensitized solar cells," Energy and Environmental Science, vol. 6, no. 12, pp. 3439-3466, 2013.

[132] N. Jiang, T. Sumitomo, T. Lee et al., "High temperature stability of dye solar cells," Solar Energy Materials \& Solar Cells, vol. 119, pp. 36-50, 2013.

[133] S. M. Zakeeruddin and M. Grätzel, "Solvent-free ionic liquid electrolytes for mesoscopic dye-sensitized solar cells," Advanced Functional Materials, vol. 19, pp. 2187-2202, 2009.

[134] F. Sauvage, S. Chhor, A. Marchioro, J.-E. Moser, and M. Graetzel, "Butyronitrile-based electrolyte for dye-sensitized solar cells," Journal of the American Chemical Society, vol. 133, no. 33, pp. 13103-13109, 2011.

[135] Q. Yu, D. Zhou, Y. Shi, X. Si, Y. Wang, and P. Wang, "Stable and efficient dye-sensitized solar cells: photophysical and electrical characterizations," Energy and Environmental Science, vol. 3, no. 11, pp. 1722-1725, 2010.

[136] A. Hinsch, J. M. Kroon, R. Kern et al., "Long-term stability of dye-sensitised solar cells," Progress in Photovoltaics: Research and Applications, vol. 9, no. 6, pp. 425-438, 2001.

[137] N. Kato, Y. Takeda, K. Higuchi et al., "Degradation analysis of dye-sensitized solar cell module after long-term stability test under outdoor working condition," Solar Energy Materials and Solar Cells, vol. 93, no. 6-7, pp. 893-897, 2009.

[138] E. Leonardi, S. Penna, T. M. Brown, A. di Carlo, and A. Reale, "Stability of dye-sensitized solar cells under light soaking test," Journal of Non-Crystalline Solids, vol. 356, no. 37-40, pp. 20492052, 2010.

[139] R. Harikisun and H. Desilvestro, "Long-term stability of dye solar cells," Solar Energy, vol. 85, no. 6, pp. 1179-1188, 2011.

[140] P. Wang, S. M. Zakeeruddin, J.-E. Moser, M. K. Nazeeruddin, T. Sekigushi, and M. Graetzel, "A stable quasi-solid-state dyesensitized solar cell with an amphiphilic ruthenium sensitizer and polymer gel electrolyte," Nature Materials, vol. 2, no. 6, pp. 402-407, 2003.

[141] D. Kuang, P. Wang, S. Ito, S. M. Zakeeruddin, and M. Grätzel, "Stable mesoscopic dye-sensitized solar cells based on tetracyanoborate ionic liquid electrolyte," Journal of the American Chemical Society, vol. 128, no. 24, pp. 7732-7733, 2006.

[142] D. Kuang, C. Klein, Z. Zhang et al., "Stable, high-efficiency ionic-liquid-based mesoscopic dye-sensitized solar cells," Small, vol. 3, no. 12, pp. 2094-2102, 2007.

[143] Z. Zhang, S. Ito, J.-E. Moser, S. M. Zakeeruddin, and M. Grätze, "Influence of iodide concentration on the efficiency and stability of dye-sensitized solar cell containing non-volatile electrolyte," ChemPhysChem, vol. 10, no. 11, pp. 1834-1838, 2009. 
[144] W. Kubo, T. Kitamura, K. Hanabusa, Y. Wada, and S. Yanagida, "Quasi-solid-state dye-sensitized solar cells using room temperature molten salts and a low molecular weight gelator," Chemical Communications, no. 4, pp. 374-375, 2002.

[145] H. Matsui, K. Okada, T. Kitamura, and N. Tanabe, "Thermal stability of dye-sensitized solar cells with current collecting grid," Solar Energy Materials and Solar Cells, vol. 93, no. 6-7, pp. 11101115, 2009.

[146] H. Pettersson and T. Gruszecki, "Long-term stability of lowpower dye-sensitised solar cells prepared by industrial methods," Solar Energy Materials and Solar Cells, vol. 70, no. 2, pp. 203-212, 2001.

[147] B. Macht, M. Turrión, A. Barkschat, P. Salvador, K. Ellmer, and H. Tributsch, "Patterns of efficiency and degradation in dye sensitization solar cells measured with imaging techniques," Solar Energy Materials \& Solar Cells, vol. 73, no. 2, pp. 163-173, 2002.

[148] S. Mastroianni, A. Lembo, T. M. Brown, A. Reale, and A. Di Carlo, "Electrochemistry in reverse biased dye solar cells and dye/electrolyte degradation mechanisms," ChemPhysChem, vol. 13, no. 12, pp. 2964-2975, 2012.

[149] E. Figgemeier and A. Hagfeldt, "Are dye-sensitized nanostructured solar cells stable? An overview of device testing and component analyses," International Journal of Photoenergy, vol. 6, no. 3, pp. 127-140, 2004.

[150] A. Hagfeldt, G. Boschloo, L. Sun, L. Kloo, and H. Pettersson, "Dye-sensitized solar cells," Chemical Reviews, vol. 110, no. 11, pp. 6595-6663, 2010.

[151] M. Flasque, A. N. Van Nhien, J. Swiatowska, A. Seyeux, C. Davoisne, and F. Sauvage, "Interface stability of a $\mathrm{TiO}_{2} / 3$ methoxypropionitrile-based electrolyte: first evidence for solid electrolyte interphase formation and implications," ChemPhysChem, vol. 15, no. 6, pp. 1126-1137, 2014.

[152] K. F. Jensen, W. Veurman, H. Brandt et al., "Photospectroscopy of I3-species in Dye Solar Cells (DSC) as a test for the sealing and diffusion barrier properties of glass frit," in Proceedings of the 27th European PV Solar Energy Conference and Exhibition, pp. 2925-2929, Frankfurt, Germany, 2012.

[153] B. Muthuraaman, S. Murugesan, V. Mathew et al., "An investigation on the performance of a silver ionic solid electrolyte system for a new detergent-based nanocrystalline dye-sensitized solar cell," Solar Energy Materials and Solar Cells, vol. 92, no. 12, pp. 1712-1717, 2008.

[154] M. Gorlov and L. Kloo, "Ionic liquid electrolytes for dyesensitized solar cells," Dalton Transactions, no. 20, pp. 26552666, 2008.

[155] A. Hinsch, J. M. Kroon, R. Kern et al., "Long-term stability of dye-sensitised solar cells," Progress in Photovoltaics: Research and Applications, vol. 9, no. 6, pp. 425-438, 2001.

[156] A. G. Kontos, T. Stergiopoulos, V. Likodimos et al., "Long-term thermal stability of liquid dye solar cells," Journal of Physical Chemistry C, vol. 117, no. 17, pp. 8636-8646, 2013.

[157] H. Greijer, J. Lindgren, and A. Hagfeldt, "Resonance Raman scattering of a dye-sensitized solar cell: mechanism of thiocyanato ligand exchange," The Journal of Physical Chemistry B, vol. 105, no. 27, pp. 6314-6320, 2001.

[158] P. E. Hansen, P. T. Nguyen, J. Krake, J. Spanget-Larsen, and T. Lund, "Dye-sensitized solar cells and complexes between pyridines and iodines. A NMR, IR and DFT study," Spectrochimica Acta-Part A: Molecular and Biomolecular Spectroscopy, vol. 98, pp. 247-251, 2012.
[159] M. Flasque, A. Nguyen Van, G. Nhien, J. Swiatowska, A. Seyeux, and F. Sauvage, in Proceedings of the 6th International Conference on Hybrid and Organic Photovoltaics, Lausanne, Switzerland, May 2014.

[160] N. G. Gaylord and A. Takahashi, "Free-radical polymerization of complexed monomers. I. Mechanism of metal halide activation," Journal of Polymer Science B: Polymer Letters, vol. 6, no. 10, pp. 743-748, 1968.

[161] M. I. Asghar, K. Miettunen, S. Mastroianni, J. Halme, H. Vahlman, and P. Lund, "In situ image processing method to investigate performance and stability of dye solar cells," Solar Energy, vol. 86, no. 1, pp. 331-338, 2012.

[162] H. Tanaka, A. Takeichi, K. Higuchi et al., "Long-term durability and degradation mechanism of dye-sensitized solar cells sensitized with indoline dyes," Solar Energy Materials \& Solar Cells, vol. 93, no. 6-7, pp. 1143-1148, 2009.

[163] S. Anderson, E. C. Constable, M. P. Dare-Edwards et al., "Chemical modification of a titanium (IV) oxide electrode to give stable dye sensitisation without a supersensitiser," Nature, vol. 280, no. 5723, pp. 571-573, 1979.

[164] M. K. Nazeeruddin, A. Kay, I. Rodicio et al., "Conversion of light to electricity by cis-X2bis $\left(2,2^{\prime}\right.$-bipyridyl- $4,4^{\prime}$ dicarboxylate)ruthenium(II) charge-transfer sensitizers ( $\mathrm{X}=$ $\mathrm{Cl}-$, Br-, I-, CN-, and SCN-) on nanocrystalline titanium dioxide electrodes," Journal of the American Chemical Society, vol. 115, no. 14, pp. 6382-6390, 1993.

[165] R. Grünwald and H. Tributsch, "Mechanisms of instability in ru-based dye sensitization solar cells," Journal of Physical Chemistry B, vol. 101, no. 14, pp. 2564-2575, 1997.

[166] H. Greijer, J. Lindgren, and A. Hagfeldt, "Resonance Raman scattering of a dye-sensitized solar cell: mechanism of thiocyanato ligand exchange," Journal of Physical Chemistry B, vol. 105, no. 27, pp. 6314-6320, 2001.

[167] P. E. Hansen, P. T. Nguyen, J. Krake, J. Spanget-Larsen, and T. Lund, "Dye-sensitized solar cells and complexes between pyridines and iodines. A NMR, IR and DFT study," Spectrochimica Acta Part A: Molecular and Biomolecular Spectroscopy, vol. 98, pp. 247-251, 2012.

[168] N. T. Hoang, N. T. P. Thoa, and T. Lund, "Thermal degradation kinetics of solar cell dye N719 bound to nanocrystalline $\mathrm{TiO}_{2}$ particles," Advances in Natural Sciences, vol. 1, no. 10, pp. 51-58, 2009.

[169] H. T. Nguyen, H. M. Ta, and T. Lund, "Thermal thiocyanate ligand substitution kinetics of the solar cell dye N719 by acetonitrile, 3-methoxypropionitrile, and 4-tert-butylpyridine," Solar Energy Materials and Solar Cells, vol. 91, no. 20, pp. 19341942, 2007.

[170] M. Thomalla and H. Tributsch, "Chromatographic studies of photodegradation of $\mathrm{RuL}_{2}(\mathrm{SCN})_{2}$ in nanostructured dyesensitization solar cells," Comptes Rendus Chimie, vol. 9, no. 5-6, pp. 659-666, 2006.

[171] F. Nour-Mohammadi, H. T. Nguyen, G. Boschloo, and T. Lund, "An investigation of the photosubstitution reaction between N719-dyed nanocrystalline $\mathrm{TiO}_{2}$ particles and 4-tertbutylpyridine," Journal of Photochemistry and Photobiology A: Chemistry, vol. 187, no. 2-3, pp. 348-355, 2007.

[172] P. Tuyet Nguyen, R. Degn, H. Thai Nguyen, and T. Lund, "Thiocyanate ligand substitution kinetics of the solar cell dye Z-907 by 3-methoxypropionitrile and 4-tert-butylpyridine at elevated temperatures," Solar Energy Materials \& Solar Cells, vol. 93, no. 11, pp. 1939-1945, 2009. 
[173] P. Tuyet Nguyen, A. Rand Andersen, E. Morten Skou, and T. Lund, "Dye stability and performances of dye-sensitized solar cells with different nitrogen additives at elevated temperatures-can sterically hindered pyridines prevent dye degradation?" Solar Energy Materials and Solar Cells, vol. 94, no. 10, pp. 1582-1590, 2010.

[174] O. Kohle, M. Graetzel, A. F. Meyer, and T. B. Meyer, "The photovoltaic stability of, bis(isothiocyanato)ruthenium(II)-bis2, $2^{\prime}$ bipyridine- $4,4^{\prime}$-dicarboxylic acid and related sensitizers," Advanced Materials, vol. 9, no. 11, pp. 904-906, 1997.

[175] M. Grätzel, "Photovoltaic performance and long-term stability of dye-sensitized meosocopic solar cells," Comptes Rendus Chimie, vol. 9, no. 5-6, pp. 578-583, 2006.

[176] K. Fredin, K. F. Anderson, N. W. Duffy et al., "Effect on cell efficiency following thermal degradation of dye-sensitized mesoporous electrodes using N719 and D5 sensitizers," Journal of Physical Chemistry C, vol. 113, no. 43, pp. 18902-18906, 2009.

[177] S. Mikoshiba, S. Murai, H. Sumino, T. Kado, D. Kosugi, and S. Hayase, "Ionic liquid type dye-sensitized solar cells: increases in photovoltaic performances by adding a small amount of water," Current Applied Physics, vol. 5, no. 2, pp. 152-158, 2005.

[178] D. F. Watson and G. J. Meyer, "Electron injection at dyesensitized semiconductor electrodes," Annual Review of Physical Chemistry, vol. 56, pp. 119-156, 2005.

[179] M. R. Hoffmann, S. T. Martin, W. Choi, and D. W. Bahnemann, "Environmental applications of semiconductor photocatalysis," Chemical Reviews, vol. 95, no. 1, pp. 69-96, 1995.

[180] S. T. Martin, H. Herrmann, W. Y. Choi, and M. R. Hoffmann, "Time-resolved microwave conductivity. Part 1.- $\mathrm{TiO}_{2}$ photoreactivity and size quantization," Journal of the Chemical Society, Transactions, vol. 90, pp. 3315-3322, 1994.

[181] C. C. Chen, X. Z. Li, W. H. Ma, J. C. Zhao, H. Hidaka, and N. Serpone, "Effect of transition metal ions on the $\mathrm{TiO}_{2}-$ assisted photodegradation of dyes under visible irradiation: a probe for the interfacial electron transfer process and reaction mechanism," The Journal of Physical Chemistry B, vol. 106, no. 2, pp. 318-324, 2002.

[182] A. Kraft, H. Hennig, A. Herbst, and K.-H. Heckner, "Changes in electrochemical and photoelectrochemical properties of tindoped indium oxide layers after strong anodic polarization," Journal of Electroanalytical Chemistry, vol. 365, no. 1-2, pp. 191196, 1994. 

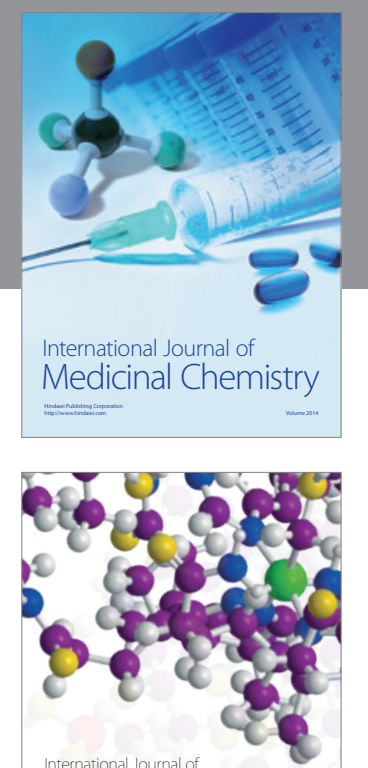

\section{Carbohydrate} Chemistry

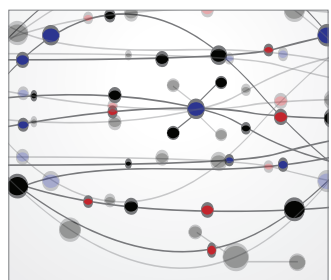

The Scientific World Journal
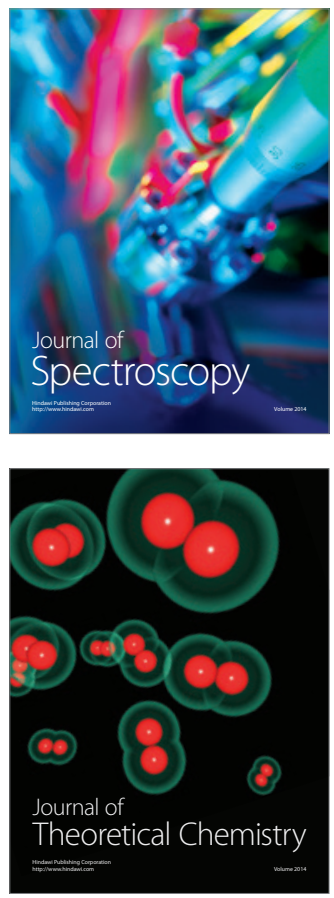
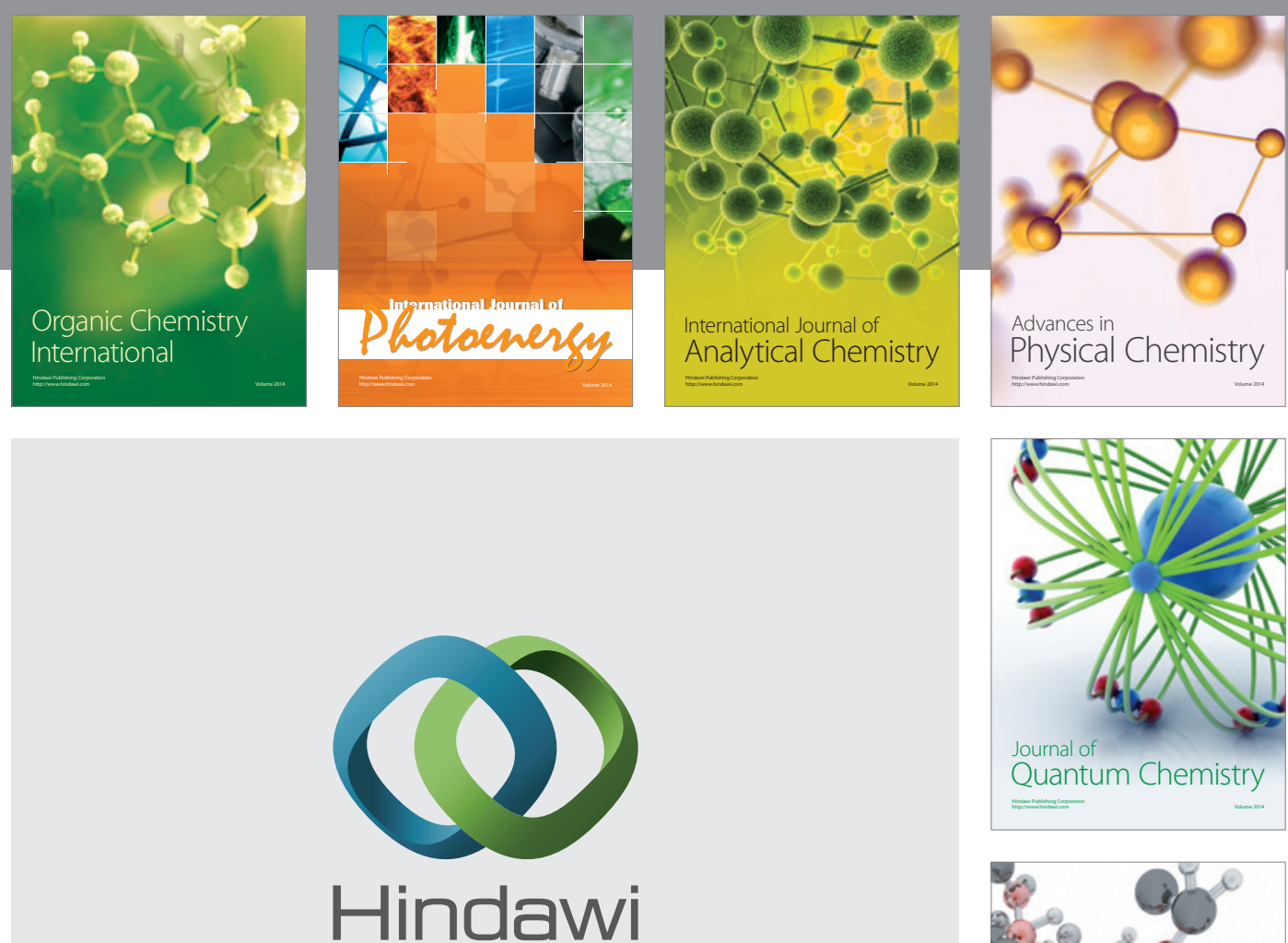

Submit your manuscripts at

http://www.hindawi.com

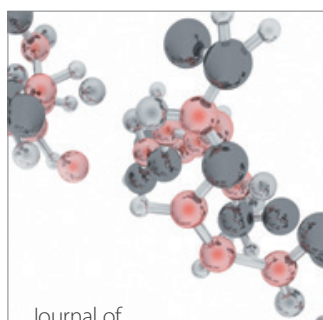

Analytical Methods

in Chemistry

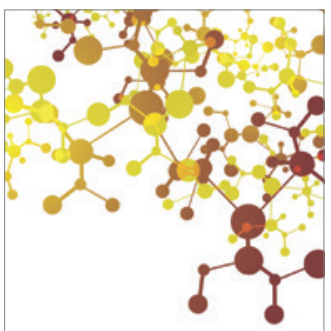

Journal of

Applied Chemistry

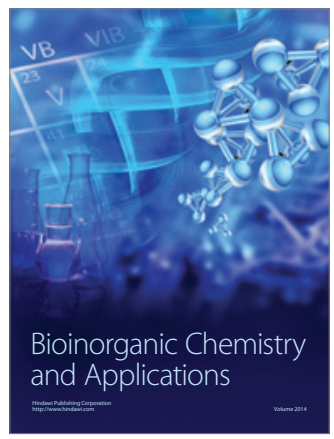

Inorganic Chemistry
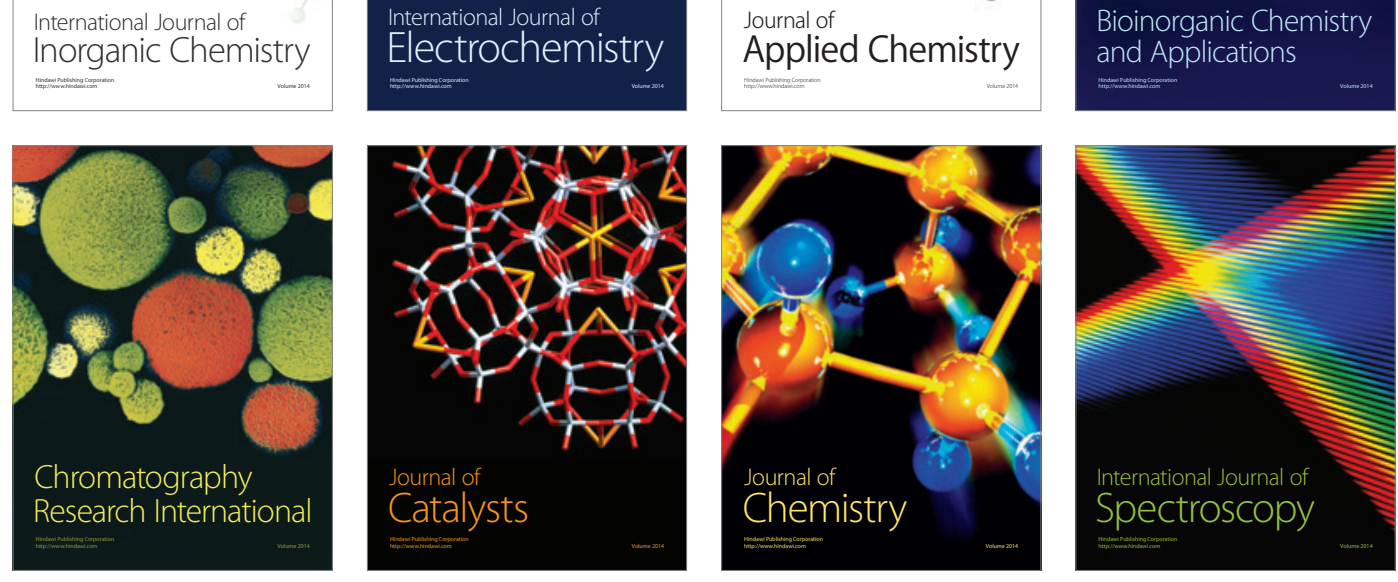